\title{
Petrografia, química mineral e litoquímica de diques máficos cambrianos do extremo oriental do estado da Paraíba
}

\author{
Vidyã Vieira Almeida ${ }^{1}$ \& Maria Helena Bezerra Maia Hollanda ${ }^{1}$
}

\begin{abstract}
Resumo O enxame de diques máficos da região de Itabaiana $(\mathrm{PB})$ está geologicamente inserido no domínio da Zona Transversal, na porção oriental da Província Borborema. Compreende dois conjuntos individualizados de diques deci- a centimétricos em largura, que ocorrem afastados cerca de $40 \mathrm{~km}$. Suas características geoquímicas permitiram classificá-los como basaltos a andesitos, incluindo dominantemente basaltos andesíticos sub-alcalinos, com afinidade toleítica. De forma geral, os diques apresentam associação mineral dominada por plagioclásio labradorita, titano-augita (por vezes com lamelas de pigeonita) e olivina $\left(\mathrm{Fo}_{76-84}\right)$, os quais compõem a matriz, também ocorrendo como microfenocristais. Feições de alteração tardi-magmática são comuns nos diques, as quais são representadas por neoformação de fases minerais secundárias como iddingsita, bowlingita e carbonato. O padrão geoquímico para elementos menores (traços e terras-raras) mostra enriquecimento moderado em $\mathrm{Rb}, \mathrm{Ba}$, Th, K e terras-raras leves, e em menor proporção em $\mathrm{Zr}$, Hf, Ti, em relação ao condrito. Pequenas diferenças em termos de fracionamento $(\mathrm{La} / \mathrm{Yb})_{\mathrm{N}}$ nos espectros ETR sugerem variações nas taxas de fusão parcial da fonte que pode tentativamente ser admitida como o manto litosférico.
\end{abstract}

Palavras-chave: Província Borborema, Zona Transversal, Cambriano, Magmatismo Máfico.

\begin{abstract}
Petrography, mineral chemistry and lithochemistry of Cambrian mafic dykes from Paraiba State (NE Brazil). The Itabaiana mafic dike swarm (Paraíba State) is inserted in the Transversal Zone domain at eastern Borborema Province (NE Brazil). It comprises two dike sets of deci- to centimetric dimension in width, which are $c .40 \mathrm{~km}$ far from. Dikes are geochemically basalts to andesites, but dominantly including andesite basalts with sub-alkaline, tholeiitic affinity. As a whole, the mineralogical assembly is represented by labradorite, titano-augite and olivine $\left(\mathrm{Fo}_{76-84}\right)$, which occur as fine-grained groundmass as well microfenocristals. Iddingsite and bowlingite are pervasive secondary mineral phases replacing olivine and pyroxene. Carbonate occurs filling vesicles, and is also a common mineral phase in the studied dikes. Minor and rare earth spectra are similar for all dikes, and are characterized by moderate, chondrite-related, enrichment in $\mathrm{Rb}, \mathrm{Ba}$, $\mathrm{Th}, \mathrm{K}$ and light rare earth elements, and in minor extent in $\mathrm{Zr}$, Hf and Ti. Differences in respect to $(\mathrm{La} / \mathrm{Yb})_{\mathrm{N}} \mathrm{ra}-$ tios suggest small variation in partial melting rates from a common source that could be lithospheric mantle.
\end{abstract}

Keywords: Borborema Province, Transversal Zone, Cambrian, Mafic Magmatism.

INTRODUÇÃ̃o A existência de enxames de diques máficos nas imediações da cidade de Itabaiana (PB) foi inicialmente cartografada por estudantes de Geologia da UFPE (1980), em trabalho de mapeamento geológico conduzido pelos professores B. B. Brito Neves, R. Pessoa e P. Gomes. Na época, a interpretação conferida a tal magmatismo era de um evento cretácico, provavelmente correspondendo à extensão meridional do magmatismo Rio Ceará-Mirim (Bellieni et al. 1992; Hollanda et al. 2006), contemporâneo à abertura do Rift Potiguar (estado do Rio Grande do Norte). Informações detalhadas acerca de suas características petrográficas, litoquímicas, geocronológicas ou de qualquer outra natureza não constituíram objetivo daquele reconhecimento inicial. Em trabalhos de campo recentes, B. B. Brito Neves individualizou dois sítios de ocorrência de diques máficos na referida região: Fazenda Cajazeiras, oeste da cidade de Itabaiana, e Fazenda Maravilha, aproximadamente $40 \mathrm{~km}$ a norte dessa cidade, nas imediações do povoado de Mulungu (área localizada na Fig. 1). A cartografia detalhada desses corpos é especialmente dificultada por não terem expressão topográfica e por apresentarem espessura na ordem de valores deci- a centimétricos. Características de campo comuns observadas nos dois sítios de ocorrência consistem em: (i) os diques estão geograficamente situados próximos às bordas de dois grábens terciários - Cariatá e Miriri (B. B. Brito Neves, comun. verbal), e (ii) estão alinhados segundo trend WNW-ESE $\left(110^{\circ}-125^{\circ}\right.$ Azimute), seccionando a estruturação regional impressa em ortognaisses e rochas supracrustais que representam seu embasamento.

$\mathrm{O}$ primeiro estudo direcionado aos diques da região de Itabaiana, especificamente aqueles da Fazenda Cajazeiras, foi a datação radiométrica pelo método ${ }^{40} \mathrm{Ar} /{ }^{39} \mathrm{Ar}$ realizada pelo Dr. Paulo Vasconcelos. Os alvos foram duas amostras cedidas por B. B. Brito Neves, cujas idades definem platôs em c. 525 Ma. Essa infor- 


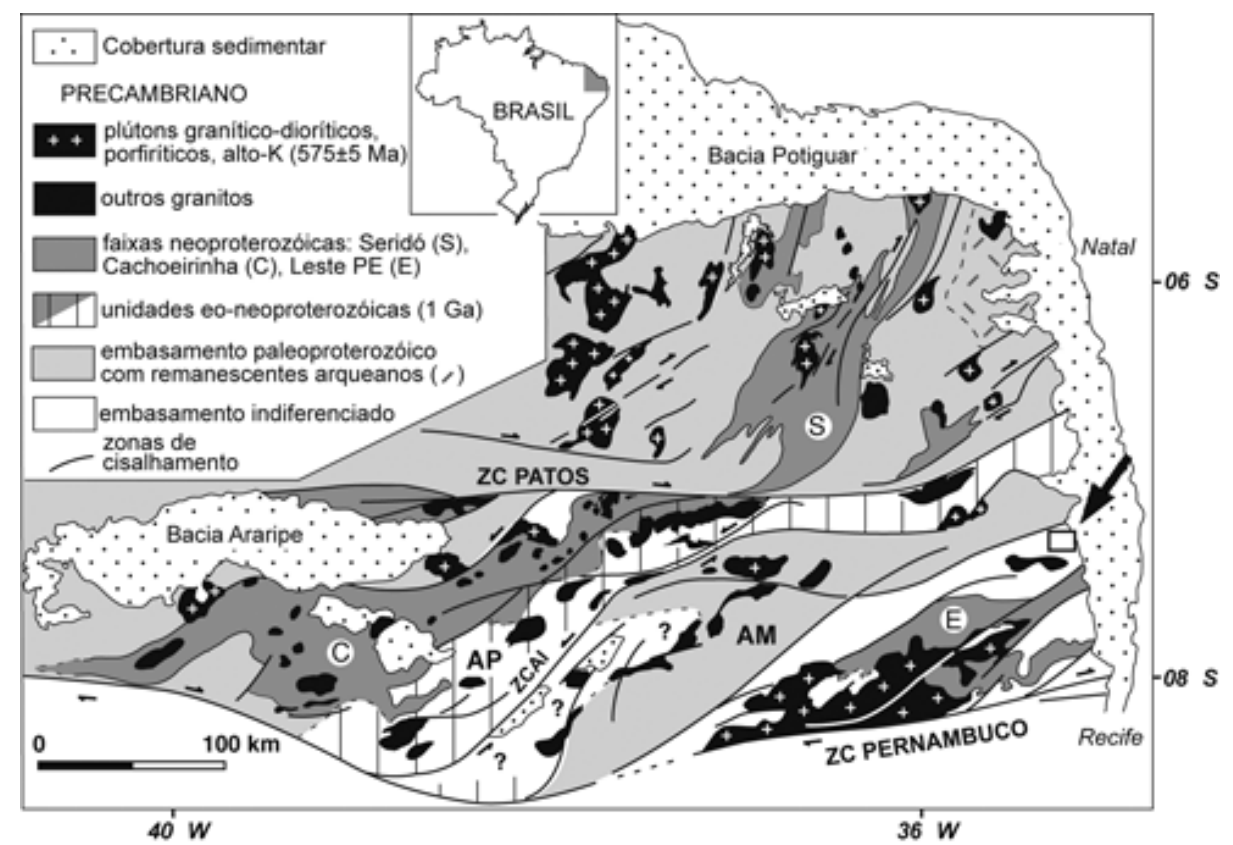

Figura 1 - Mapa geológico simplificado da porção oriental da Província Borborema, destacando os domínios estruturais Rio Grande do Norte, a norte do Lineamento Patos, e Zona Transversal, a qual engloba os domínios Alto Pajeú (AP) e Alto Moxotó (AM), entre os lineamentos Patos e Pernambuco. O quadrado à direita da figura (indicado pela seta) localiza a área de ocorrência dos diques.

mação cronológica instigou uma equipe de pesquisadores do Instituto de Astronomia, Meteorologia e Geofísica (IAG) da USP, a executar levantamento paleomagnético sistemático nos diques com intuito de estabelecer um pólo para o Gondwana durante o Cambriano. Dados geocronológicos e discussão sobre a paleogeografia do Gondwana obtidos a partir desses diques máficos estão publicados em Trindade et al. (2006).

Apesar do acervo de dados qualitativos específicos, geocronológicos e paleomagnéticos, informações básicas incluindo aspectos petrográficos e litoquímicos não estavam, até o momento, disponíveis. Dada sua importância como um dos poucos exemplos conhecidos de magmatismo cambriano e, em adição, de natureza básica na Província Borborema, esse artigo reúne dados petrográficos (incluindo química mineral) e litoquímicos sobre os diques máficos da região de Itabaiana, com intenção de ampliar o volume de informações geológicas para este magmatismo fissural. Tal estudo foi conduzido no mesmo conjunto de amostras utilizado para análise paleomagnética, cujas coordenadas geográficas estão listadas na tabela 1 .

CONTEXTO GEOLÓGICO A Província Borborema, definida inicialmente por Almeida et al. (1977), é uma entidade geotectônica constituída por seqüências supracrustais meso- e neoproterozóicas, separadas entre si por blocos de embasamento gnáissico-migmatítico paleo- a mesoproterozóicos. Toda a província foi intensamente retrabalhada durante a orogênese Brasiliana, cuja principal feição geológica constitui um mosaico de zonas de cisalhamento E-W e N-NE, associado a volumoso magmatismo bimodal. Após o Precambriano,
Tabela 1 - Coordenadas geográficas (latitude e longitude) dos diques máficos estudados.

\begin{tabular}{|c|c|c|}
\hline Coordenada & Latitude & Longitude \\
\hline $\begin{array}{l}\text { SíTIO I } \\
\text { Inclui os diques CAJ-01 a CAJ }\end{array}$ & $\begin{array}{l}35^{\circ} 24^{\prime} 135^{\prime \prime} \mathrm{S} \\
07\end{array}$ & $07^{0} 20^{\prime} 337^{\prime \prime} \mathrm{W}$ \\
\hline $\begin{array}{l}\text { SÍTIO II } \\
\text { Inclui os diques CAJ-08 e CAJ }\end{array}$ & $\begin{array}{l}35^{0} 24^{\prime} 173^{\prime \prime} \mathrm{S} \\
99\end{array}$ & $07^{0} 20^{\prime} 310^{\prime \prime} \mathrm{W}$ \\
\hline $\begin{array}{l}\text { SÍTIO III } \\
\text { Inclui os diques } C A J-10 \text { a } C A J\end{array}$ & $\begin{array}{l}35^{\circ} 22^{\prime} 510^{\prime \prime} \mathrm{S} \\
12\end{array}$ & $07^{0} 19^{\prime} 970^{\prime \prime} \mathrm{W}$ \\
\hline $\begin{array}{l}\text { SÍTIO IV } \\
\text { Inclui somente o dique CAJ-13 }\end{array}$ & $35^{\circ} 22^{\prime} 443^{\prime \prime} \mathrm{S}$ & $07^{0} 19^{\prime} 969^{\prime \prime} \mathrm{W}$ \\
\hline $\begin{array}{l}\text { SÍTIO V } \\
\text { Inclui os diques } C A J-14 \text { a } C A J\end{array}$ & $\begin{array}{l}35^{0} 22^{\prime} 311^{\prime \prime} \mathrm{S} \\
18\end{array}$ & $07^{\circ} 20^{\prime} 102^{\prime \prime} \mathrm{W}$ \\
\hline $\begin{array}{l}\text { SÍTIO VI } \\
\text { Inclui os diques CAJ-19 e CAJ }\end{array}$ & $\begin{array}{l}35^{\circ} 24^{\prime} 198^{\prime \prime} \mathrm{S} \\
20\end{array}$ & $07^{0} 20^{\prime} 309^{\prime \prime} \mathrm{W}$ \\
\hline $\begin{array}{l}\text { SíTIO VII } \\
\text { Inclui os diques MR-01 a MR- }\end{array}$ & $35^{0} 26^{\prime} 564^{\prime \prime} \mathrm{S}$ & $07^{0} 01^{\prime} 676^{\prime \prime} \mathrm{W}$ \\
\hline
\end{tabular}

especificamente no período transicional entre Proterozóico-Fanerozóico, a província foi afetada por atividade magmática representada por derrames, enxames de diques e plútons, ácidos a básicos, geneticamente relacionados (ou não) ao desenvolvimento de bacias intracratônicas (Brito Neves 1988). Dentre as poucas ocorrências recentemente cartografadas está incluído o enxame de diques máficos de Itabaiana, geologicamente inserido dentro dos limites do Terreno Alto-Moxotó (TAM), embasamento paleoproterozóico (c. 2,0-2,2 Ga) de alto grau que aflora na porção oriental da Zona Transversal 
(Santos 1995; Brito Neves et al. 2001a, b) (Fig. 1).

A porção oriental da Zona Transversal - o Terreno Alto Moxotó A sub-província Zona Transversal inclui várias seqüências supracrustais de idades meso- (c. $1,0 \mathrm{Ga})$ e neoproterozóicas (c. 0,6 Ga) atribuídas, respectivamente, à atuação dos eventos Cariris Velhos e Brasiliano (Brito Neves et al. 1995). O TAM é constituído por ortognaisses graníticos a tonalíticos, freqüentemente migmatizados, com intercalações de rochas anfibolíticas, cálcio-silicatadas, pelíticas e mesmo ultramáficas, de idade paleoproterozóica, e supracrustais mesoproterozóicas (Fernandes 1997). Todo esse conjunto litológico está agrupado em duas unidades estratigráficas maiores: (i) Complexo Floresta, constituído dominantemente por metaplutônicas, e (ii) Complexo Sertânia, compreendendo essencialmente metassedimentos aluminosos e metavulcânicas (Santos 1996, 1999). Plútons granitóides neoproterozóicos intrudem indiscriminadamente ambas as unidades.

O Complexo Floresta reúne metaplutônicas com anfibólio \pm biotita, de composição dominantemente quartzodiorítica e tonalítica, com intercalações de rochas metamáficas anfibolitizadas (Santos 1995). Segundo E.J. Santos, suas características e relações estratigráficas com seqüências metavulcanossedimentares proximais (Serra do Sítio, Lagoa das Contendas) sugerem que esse complexo representaria o "...testemunho de uma antiga microplaca, desmembrada por processos tafrogenéticos e orogênicos subseqüentes". O Complexo Sertânia, por sua vez, foi descrito originalmente por Santos (inédito) e representa a unidade típica do TAM, ocorrendo estritamente neste terreno. Constitui uma seqüência dominantemente sedimentar com um componente vulcânico subordinado, metamorfisada em condições de fácies anfibolito superior. Em sua área-tipo é composto por granada-biotita ( \pm sillimanita) paragnaisses com intercalações de mármores, quartzitos, rochas calciosilicáticas e anfibolitos, variavelmente migmatizados (Santos et al. 2004).

Idades U/Pb SHRIMP em zircões detríticos de metapelito do Complexo Sertânia mostraram estreita concordância com as idades obtidas para uma rocha vulcanoclástica deste mesmo complexo e um ortognaisse do Complexo Floresta (Santos et al. 2004). Tanto o ortognaisse como a unidade vulcanoclástica possuem idades em torno de 2,0 Ga, coerentes com as idades ${ }^{207} \mathrm{~Pb} /{ }^{206} \mathrm{~Pb}$ entre $2,2-1,95 \mathrm{Ga}$ obtidas nos zircões detríticos do metapelito Sertânia. Segundo aqueles autores, essa coincidência sugere que: (i) ambos os complexos compartilhariam uma história evolutiva comum, préevento Cariris Velhos, e (ii) uma fonte potencial para os sedimentos Sertânia seria o próprio complexo de embasamento Floresta, paleoproterozóico. Essa última indicação seria endossada pela análise morfológica dos zircões detríticos que aponta para uma fonte ígnea homogênea, proximal (zircões prismáticos, com pouco arredondamento). Idades modelo Sm-Nd também são coerentes, em torno de 2,7 Ga (Brito Neves et al. 2001b).

Ao TAM é atribuída uma evolução policíclica, a qual teria culminado com expressiva granitogênese e intenso retrabalhamento tectono-termal durante o Ciclo Brasiliano (630-570 Ma). A deformação que acompanhou o alojamento dos magmas nesse período geológico teria moldado toda trama estrutural do TAM, bem como de toda a Província Borborema, convergindo para as grandes zonas de cisalhamento de direção NE-SW e E-W (Archanjo et al. 2002).

PETROGRAFIA E QUÍMICA MINERAL O enxame de diques máficos de Itabaiana apresenta trend geral WNW-ESE (raramente N-S), e espessuras variando entre 15 centímetros até 1 metro (Fig. 2). Ma-
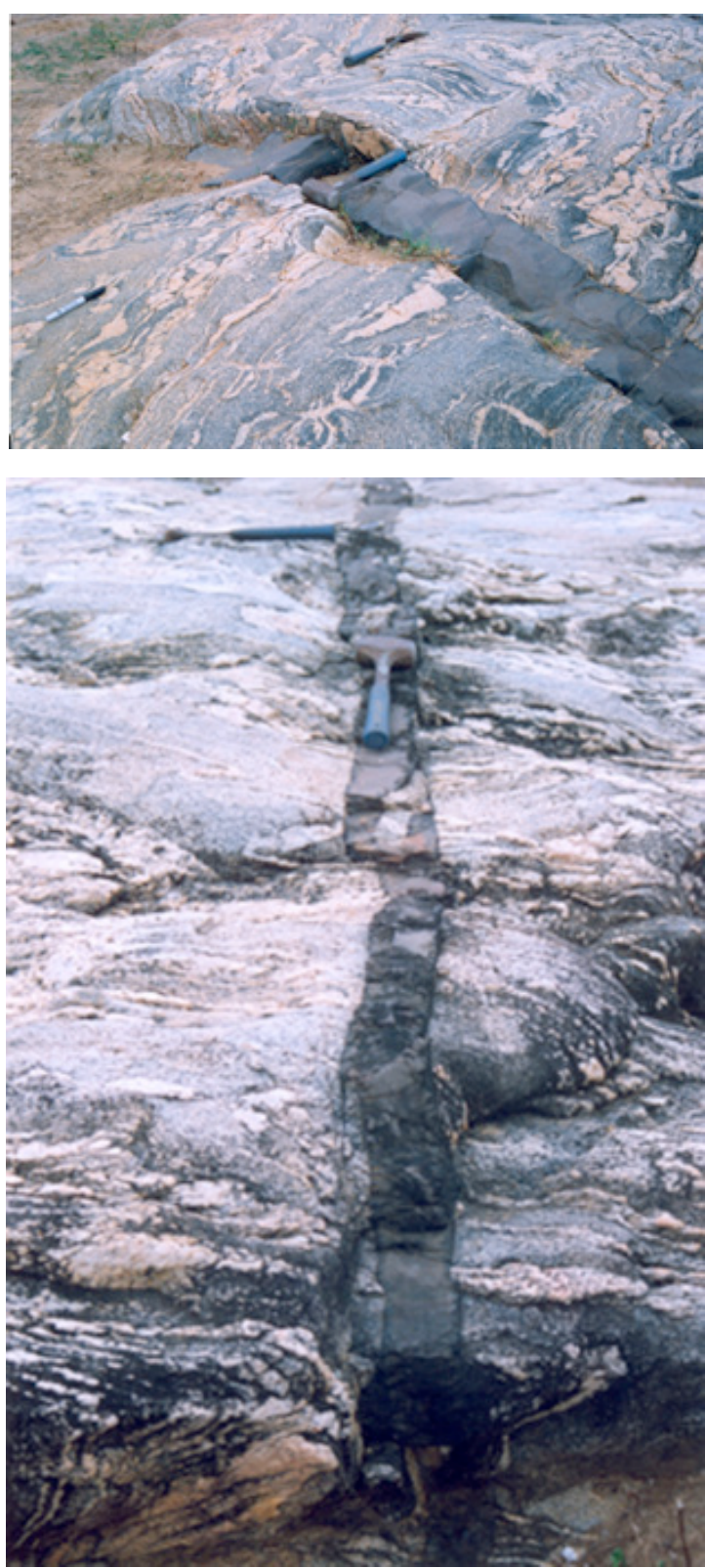

Figura 2 - Aspectos de campo dos diques máficos da região de Itabaiana. Em (A) dique intrusivo no embasamento gnáissico, cortando ortogonalmente a estrutura regional, e (B) dique com xenólitos da rocha gnáissica encaixante. Em ambas as fotos os diques mostram margens de resfriamento. 
croscopicamente, os diques têm aspecto fresco, sem quaisquer evidências visíveis de alterações supergênica ou hidrotermal. Apresentam coloração escura dada por matriz dominantemente afanítica (por vezes fanerítica fina), a qual pode envolver microfenocristais isolados de plagioclásio e fases minerais máficas. É comum a presença de margens de resfriamento, indicando nível raso de intrusão.

A proporção modal de microfenocristais e matriz foi estimada mediante análise visual e contagem automática de pontos em apenas algumas amostras; os dados são apresentados na tabela 2. Microfenocristais são representados essencialmente por plagioclásio (4-5\%, em duas amostras), piroxênio (em torno de $1 \%$, em apenas uma amostra) e olivina (em torno de $2 \%$, também em apenas uma amostra). A matriz, em todas as amostras investigadas, é composta por plagioclásio, piroxênio e menores proporções de óxidos de Fe-Mg-Ti e vidro.

As características petrográficas observadas nas seções delgadas investigadas permitiram, a priori, subdividir os diques máficos em três grupos. Essa subdivisão é especialmente fundamentada na presença (ou não) de microfenocristais e sua tipologia. Os grupos foram definidos como diques contendo as associações de: (1) microfenocristais de plagioclásio+clinopiroxênio $+o l i v$ ina, (2) microfenocristais de olivina( \pm ortopiroxênio) e (3) diques faneríticos. Essa classificação traz implícita uma clara distinção composicional entre os diques dos grupos (1) e (2), ao menos em termos de teores de Ca. A seguir estão descritos os principais aspectos petrográficos dos diques, incluindo alguns dados de química mineral, os quais foram medidos em núcleos e bordas de microfenocristais e em micrólitos da matriz. Tendo em vista o grau variável de alteração evidente somente após o estudo microscópico, a obtenção dos dados de química mineral restringiu-se a um conjunto de seis amostras, onde as texturas/aspectos primários estão melhor preservados. A variação completa da composição das principais fases minerais observadas (matriz e microfenocristais) é apresentada nas tabelas 3.(A, B, C, D).

Diques contendo microfenocristais de plagioclásio+ olivina \pm clinopiroxênio Este grupo compreende parte dos diques máficos que ocorrem na Fazenda Cajazeiras - CAJ-01 a -7, CAJ-10 e CAJ-19. Apresentam matriz inequigranular fina $(0,2$ a $0,8 \mathrm{~mm})$, dominantemente constituída por cristais euédricos a subeuédricos de plagioclásio e clinopiroxênio e, em menor proporção, olivina; vidro e óxidos de Fe-Mg-Ti ocorrem nos interstícios entre esses cristais. A textura geral é intergranular-intersertal, sem orientação de fluxo evidente; exceção é o dique CAJ-04, onde a forte orientação determinada especialmente pelos micrólitos de plagioclásio caracteriza textura traquítica (Fig. 3.A). Plagioclásio, na matriz, tem $\mathrm{An}_{50-60}$ (labradorita) (Fig. 4.A), e comumente apresentam morfologia tipo swallow-tail, tipicamente relacionada a resfriamento rápido. Clinopiroxênio tem $\mathrm{Wo}_{43-47} \mathrm{En}_{34-36} \mathrm{Fs}_{17-23}$ (Fig. 5.A), indicando uma estreita variação composicional entre diopsídio e titano-augita $\left(\mathrm{TiO}_{2}>2 \%\right)$.

Microfenocristais de plagioclásio estão perva-

Tabela 2 - Estimativa das proporções modais das fases minerais constituintes (microfenocristais e matriz) em alguns dos diques máficos das fazendas Cajazeiras e Maravilha.

\begin{tabular}{|c|c|c|c|c|c|c|c|c|c|c|c|c|c|c|c|c|}
\hline Dique & $\begin{array}{c}\text { CAJ- } \\
01 \\
\end{array}$ & $\begin{array}{c}\text { CAJ- } \\
02 \\
\end{array}$ & $\begin{array}{c}\text { CAJ- } \\
03^{*}\end{array}$ & $\begin{array}{c}\text { CAJ- } \\
04 \\
\end{array}$ & $\begin{array}{c}\text { CAJ- } \\
05 \\
\end{array}$ & $\begin{array}{c}\text { CAJ- } \\
06\end{array}$ & $\begin{array}{c}\text { CAJ- } \\
10^{*}\end{array}$ & $\begin{array}{c}\text { CAJ- } \\
11 \\
\end{array}$ & $\begin{array}{c}\text { CAJ- } \\
12^{*}\end{array}$ & $\begin{array}{c}\text { CAJ- } \\
15^{*}\end{array}$ & $\begin{array}{c}\text { MR- } \\
01\end{array}$ & $\begin{array}{c}\text { MR- } \\
03\end{array}$ & $\begin{array}{l}\text { MR- } \\
04 *\end{array}$ & $\begin{array}{c}\text { MR- } \\
05\end{array}$ & $\begin{array}{c}\text { MR- } \\
07\end{array}$ & $\begin{array}{c}\text { MR- } \\
08 \\
\end{array}$ \\
\hline \multicolumn{17}{|l|}{$\begin{array}{l}\text { Micro- } \\
\text { fenocristal }\end{array}$} \\
\hline Plagioclásio & 35 & 35 & 35 & 35 & 10 & 20 & 70 & - & - & - & - & - & - & - & - & - \\
\hline Olivina & 55 & 55 & 50 & 60 & 40 & 70 & 15 & 100 & 100 & 70 & - & - & - & - & - & - \\
\hline Piroxênio & 10 & 10 & 15 & 5 & 50 & 10 & 15 & - & - & 30 & - & - & - & - & - & - \\
\hline Matriz & & & & & & & & & & & & & & & & \\
\hline Plagioclásio & 55 & 60 & 40 & 55 & 55 & 50 & 50 & 60 & 40 & 45 & 65 & 70 & 55 & 70 & 75 & 60 \\
\hline Olivina & 5 & 5 & 5 & 5 & 5 & 10 & 10 & 5 & 10 & 5 & 5 & $<5$ & $<5$ & $<5$ & 5 & $<5$ \\
\hline Piroxênio & 10 & 15 & 20 & 15 & 10 & 20 & 25 & 20 & 35 & 35 & $<5$ & 5 & 35 & 5 & $<5$ & 5 \\
\hline Vidro+opacos & 10 & 5 & 15 & 5 & 15 & 5 & 10 & 5 & 10 & 10 & 5 & 5 & 5 & 5 & 5 & 10 \\
\hline $\begin{array}{l}\text { Fases } \\
\text { secundárias }\end{array}$ & 20 & 15 & 20 & 20 & 15 & 15 & 5 & 10 & 5 & $<5$ & 20 & 20 & 5 & 20 & 15 & 20 \\
\hline
\end{tabular}

Todos os valores são dados em percentagem.

* amostras cuja proporção modal foi estabelecida por contagem automática. 
Tabela 3.A - Composições químicas de plagioclásio (fenocristais e matriz) em amostras de diques das fazendas Cajazeiras e Maravilha.

\begin{tabular}{|c|c|c|c|c|c|c|c|c|c|c|c|c|c|c|c|c|}
\hline \multirow{2}{*}{$\begin{array}{l}\text { Dique } \\
\text { Análise }\end{array}$} & \multicolumn{2}{|c|}{ CAJ-03 } & \multicolumn{6}{|c|}{ CAJ-05 } & \multicolumn{8}{|c|}{ CAJ-12 } \\
\hline & \multirow{3}{*}{$\begin{array}{c}1 \\
\text { matriz }\end{array}$} & \multirow{3}{*}{$\begin{array}{c}2 \\
\text { matriz }\end{array}$} & \multirow{2}{*}{\multicolumn{2}{|c|}{$\begin{array}{l}1 \\
\text { fenocristal }\end{array}$}} & \multirow{2}{*}{\multicolumn{2}{|c|}{$\begin{array}{l}2 \\
\text { fenocristal }\end{array}$}} & \multirow{2}{*}{\multicolumn{2}{|c|}{$\begin{array}{l}3 \\
\text { fenocristal }\end{array}$}} & \multirow{4}{*}{$\begin{array}{c}1 \\
\text { matriz } \\
53,27\end{array}$} & \multirow{4}{*}{$\begin{array}{c}2 \\
\text { matriz } \\
52,38\end{array}$} & \multirow{4}{*}{$\begin{array}{c}3 \\
\text { matriz } \\
53,53\end{array}$} & \multirow{4}{*}{$\begin{array}{c}4 \\
\text { matriz } \\
52,72\end{array}$} & \multirow{4}{*}{$\begin{array}{c}5 \\
\text { matriz } \\
53,00\end{array}$} & \multirow{4}{*}{$\begin{array}{c}6 \\
\text { matriz } \\
52,55\end{array}$} & \multirow{4}{*}{$\begin{array}{c}7 \\
\text { matriz } \\
51,38\end{array}$} & \multirow{4}{*}{$\begin{array}{c}8 \\
\text { matriz } \\
52,32\end{array}$} \\
\hline & & & & & & & & & & & & & & & & \\
\hline & & & $n$ & $b$ & $n$ & $b$ & $n$ & $b$ & & & & & & & & \\
\hline $\mathrm{SiO} 2$ & 47,25 & 46,14 & 46,55 & 46,39 & 47,30 & 46,63 & 46,12 & 47,71 & & & & & & & & \\
\hline TiO2 & 2,58 & 3,28 & 3,16 & 2,67 & 2,48 & 2,30 & 2,91 & 1,53 & 0,51 & 0,45 & 0,37 & 0,39 & 0,23 & 0,60 & 0,54 & 0,68 \\
\hline $\mathrm{A} 12 \mathrm{O} 3$ & 4,38 & 6,56 & 5,79 & 5,94 & 6,08 & 5,91 & 6,17 & 5,18 & 2,23 & 2,08 & 1,85 & 2,08 & 2,48 & 2,22 & 1,96 & 2,22 \\
\hline $\mathrm{FeOt}$ & 13,16 & 9,53 & 10,92 & 10,72 & 9,27 & 9,35 & 10,54 & 10,47 & 12,38 & 14,76 & 11,49 & 13,47 & 11,78 & 14,20 & 16,11 & 14,41 \\
\hline $\mathrm{Cr} 2 \mathrm{O} 3$ & 0,09 & 0,17 & 0,11 & 0,13 & 0,21 & 0,14 & 0,32 & 0,05 & 0,38 & 0,06 & 0,34 & 0,21 & 0,46 & 0,12 & 0,00 & 0,06 \\
\hline $\mathrm{MnO}$ & 0,30 & 0,19 & 0,17 & 0,14 & 0,20 & 0,17 & 0,16 & 0,14 & 0,18 & 0,32 & 0,23 & 0,27 & 0,26 & 0,32 & 0,28 & 0,26 \\
\hline $\mathrm{MgO}$ & 11,14 & 11,74 & 12,05 & 11,92 & 12,75 & 13,61 & 12,20 & 14,08 & 27,47 & 23,11 & 28,00 & 25,68 & 26,89 & 24,48 & 22,04 & 23,36 \\
\hline $\mathrm{CaO}$ & 19,66 & 20,93 & 21,26 & 21,41 & 20,91 & 20,54 & 20,34 & 18,42 & 3,65 & 5,77 & 3,21 & 4,52 & 3,70 & 4,75 & 6,48 & 5,39 \\
\hline $\mathrm{Na} 2 \mathrm{O}$ & 0,69 & 0,60 & 0,59 & 0,62 & 0,55 & 0,55 & 0,60 & 0,53 & 0,11 & 0,12 & 0,08 & 0,12 & 0,12 & 0,10 & 0,18 & 0,14 \\
\hline $\mathrm{K} 2 \mathrm{O}$ & 0,00 & 0,00 & 0,01 & 0,00 & 0,02 & 0,00 & 0,00 & 0,94 & 0,02 & 0,02 & 0,01 & 0,02 & 0,01 & 0,00 & 0,02 & 0,03 \\
\hline Total & 99,24 & 99,15 & 100,61 & 99,95 & 99,75 & 99,19 & 99,36 & 99,03 & 100,19 & 99,06 & 99,10 & 99,47 & 98,94 & 99,34 & 98,98 & 98,88 \\
\hline TSi & 1,81 & 1,75 & 1,74 & 1,74 & 1,77 & 1,75 & 1,74 & 1,79 & 1,90 & 1,93 & 1,92 & 1,91 & 1,91 & 1,92 & 1,90 & 1,93 \\
\hline TAl & 0,20 & 0,25 & 0,26 & 0,26 & 0,23 & 0,25 & 0,26 & 0,21 & 0,09 & 0,07 & 0,08 & 0,09 & 0,09 & 0,08 & 0,09 & 0,07 \\
\hline TFe3+ & 0,00 & 0,00 & 0,01 & 0,00 & 0,00 & 0,00 & 0,00 & 0,00 & 0,01 & 0,00 & 0,00 & 0,00 & 0,00 & 0,00 & 0,01 & 0,00 \\
\hline M1Al & 0,00 & 0,04 & 0,00 & 0,01 & 0,04 & 0,01 & 0,02 & 0,02 & 0,00 & 0,02 & 0,00 & 0,00 & 0,02 & 0,01 & 0,00 & 0,02 \\
\hline M1Ti & 0,07 & 0,09 & 0,09 & 0,08 & 0,07 & 0,07 & 0,08 & 0,04 & 0,01 & 0,01 & 0,01 & 0,01 & 0,01 & 0,02 & 0,02 & 0,02 \\
\hline M1Fe3+ & 0,09 & 0,07 & 0,12 & 0,14 & 0,09 & 0,15 & 0,11 & 0,19 & 0,07 & 0,04 & 0,05 & 0,07 & 0,05 & 0,04 & 0,08 & 0,02 \\
\hline $\mathrm{M} 1 \mathrm{Fe} 2+$ & 0,20 & 0,13 & 0,12 & 0,11 & 0,09 & 0,01 & 0,10 & 0,00 & 0,00 & 0,00 & 0,00 & 0,00 & 0,00 & 0,00 & 0,00 & 0,00 \\
\hline $\mathrm{M} 1 \mathrm{Cr}$ & 0,00 & 0,01 & 0,00 & 0,00 & 0,01 & 0,00 & 0,01 & 0,00 & 0,01 & 0,00 & 0,01 & 0,01 & 0,01 & 0,00 & 0,00 & 0,00 \\
\hline $\mathrm{M} 1 \mathrm{Mg}$ & 0,64 & 0,66 & 0,67 & 0,67 & 0,71 & 0,76 & 0,69 & 0,75 & 0,91 & 0,93 & 0,93 & 0,91 & 0,91 & 0,93 & 0,91 & 0,93 \\
\hline $\mathrm{M} 2 \mathrm{Mg}$ & 0,00 & 0,00 & 0,00 & 0,00 & 0,00 & 0,00 & 0,00 & 0,04 & 0,56 & 0,34 & 0,57 & 0,48 & 0,54 & 0,41 & 0,31 & 0,35 \\
\hline $\mathrm{M} 2 \mathrm{Fe} 2+$ & 0,14 & 0,10 & 0,10 & 0,09 & 0,12 & 0,13 & 0,13 & 0,13 & 0,29 & 0,42 & 0,29 & 0,33 & 0,30 & 0,39 & 0,41 & 0,42 \\
\hline M2Mn & 0,01 & 0,01 & 0,01 & 0,01 & 0,01 & 0,01 & 0,01 & 0,00 & 0,01 & 0,01 & 0,01 & 0,01 & 0,01 & 0,01 & 0,01 & 0,01 \\
\hline $\mathrm{M} 2 \mathrm{Ca}$ & 0,81 & 0,85 & 0,85 & 0,86 & 0,84 & 0,83 & 0,82 & 0,74 & 0,14 & 0,23 & 0,12 & 0,18 & 0,14 & 0,19 & 0,26 & 0,21 \\
\hline $\mathrm{M} 2 \mathrm{Na}$ & 0,05 & 0,04 & 0,04 & 0,05 & 0,04 & 0,04 & 0,04 & 0,04 & 0,01 & 0,01 & 0,01 & 0,01 & 0,01 & 0,01 & 0,01 & 0,01 \\
\hline $\mathrm{M} 2 \mathrm{~K}$ & 0,00 & 0,00 & 0,00 & 0,00 & 0,00 & 0,00 & 0,00 & 0,05 & 0,00 & 0,00 & 0,00 & 0,00 & 0,00 & 0,00 & 0,00 & 0,00 \\
\hline Total & 4,00 & 4,00 & 4,00 & 4,00 & 4,00 & 4,00 & 4,00 & 3,96 & 4,00 & 4,00 & 4,00 & 4,00 & 4,00 & 4,00 & 4,00 & 4,00 \\
\hline Wo & 43,05 & 46,66 & 45,54 & 46,07 & 45,42 & 43,78 & 44,55 & 39,79 & 7,07 & 11,61 & 6,25 & 8,87 & 7,32 & 9,47 & 12,97 & 10,92 \\
\hline En & 33,94 & 36,43 & 35,91 & 35,69 & 38,53 & 40,37 & 37,17 & 42,33 & 73,96 & 64,70 & 75,92 & 70,09 & 74,07 & 67,93 & 61,41 & 65,86 \\
\hline Fs & 23,01 & 16,92 & 18,55 & 18,24 & 16,06 & 15,85 & 18,29 & 17,88 & 18,98 & 23,70 & 17,83 & 21,05 & 18,61 & 22,60 & 25,63 & 23,22 \\
\hline
\end{tabular}

* os valores dos óxidos e teores de An(anortita), Ab(albita) e Or(ortoclásio) são dados em percentagem. Legenda: $n=$ núcleo/centro; $b=$ borda.

sivamente presentes. São, em geral, euédricos (1,0-1,5 matriz circunvizinha. Mostram composições tão homo$\mathrm{mm})$, sem quaisquer evidências de desequilíbrio com a gêneas $\left(\mathrm{An}_{52-62}\right)$ (Fig. 4.B) quanto aquelas dos micrólitos 


\begin{tabular}{|c|c|c|c|c|c|c|c|c|c|c|c|c|c|c|c|c|c|c|c|}
\hline \multirow{2}{*}{$\begin{array}{l}\text { Dique } \\
\text { Análise }\end{array}$} & \multicolumn{13}{|c|}{ CAJ-15 } & \multicolumn{4}{|c|}{ MR-04 } & \multicolumn{2}{|c|}{ MR-08 } \\
\hline & \multirow{2}{*}{\multicolumn{2}{|c|}{$\begin{array}{c}1 \\
\text { fenocristal }\end{array}$}} & \multirow{2}{*}{\multicolumn{2}{|c|}{$\begin{array}{c}2 \\
\text { fenocristal }\end{array}$}} & \multirow{2}{*}{\multicolumn{2}{|c|}{$\begin{array}{c}3 \\
\text { fenocristal }\end{array}$}} & \multirow{3}{*}{$\begin{array}{c}4 \\
\text { matriz }\end{array}$} & \multirow{3}{*}{$\begin{array}{c}5 \\
\text { matriz }\end{array}$} & \multirow{3}{*}{$\begin{array}{c}6 \\
\text { matriz }\end{array}$} & \multirow{3}{*}{$\begin{array}{c}7 \\
\text { matriz }\end{array}$} & \multirow{3}{*}{$\begin{array}{c}8 \\
\text { matriz }\end{array}$} & \multirow{3}{*}{$\begin{array}{c}9 \\
\text { matriz }\end{array}$} & \multirow{3}{*}{$\begin{array}{c}10 \\
\text { matriz }\end{array}$} & \multirow{2}{*}{\multicolumn{2}{|c|}{$\begin{array}{c}1 \\
\text { cristal }\end{array}$}} & \multirow{2}{*}{\multicolumn{2}{|c|}{$\begin{array}{c}2 \\
\text { cristal }\end{array}$}} & \multirow{2}{*}{\multicolumn{2}{|c|}{$\begin{array}{c}1 \\
\text { cristal }\end{array}$}} \\
\hline & & & & & & & & & & & & & & & & & & & \\
\hline & $n$ & $b$ & $n$ & $b$ & $n$ & $b$ & & & & & & & & $n$ & $b$ & $n$ & $b$ & $n$ & $b$ \\
\hline $\mathrm{SiO} 2$ & 54,15 & 54,62 & 54,31 & 54,50 & 54,30 & 54,17 & 53,72 & 52,92 & 53,50 & 53,35 & 53,81 & 53,96 & 53,64 & 50,74 & 51,30 & 50,48 & 50,81 & 48,84 & 49,73 \\
\hline $\mathrm{TiO} 2$ & 0,26 & 0,14 & 0,26 & 0,14 & 0,35 & 0,31 & 0,48 & 0,54 & 0,44 & 0,58 & 0,41 & 0,41 & 0,58 & 1,15 & 1,14 & 1,45 & 1,03 & 2,07 & 1,52 \\
\hline $\mathrm{A} 12 \mathrm{O} 3$ & 2,76 & 2,32 & 3,37 & 2,57 & 2,82 & 3,45 & 2,13 & 1,66 & 2,28 & 2,26 & 2,12 & 2,61 & 2,34 & 2,28 & 2,09 & 2,55 & 1,74 & 3,65 & 2,84 \\
\hline FeOt & 11,10 & 11,00 & 10,59 & 10,86 & 10,38 & 10,92 & 12,52 & 16,62 & 12,77 & 12,13 & 13,58 & 11,49 & 12,09 & 15,44 & 16,89 & 13,88 & 17,92 & 12,50 & 13,35 \\
\hline $\mathrm{Cr} 2 \mathrm{O} 3$ & 0,34 & 0,28 & 0,34 & 0,32 & 0,33 & 0,25 & 0,28 & 0,03 & 0,31 & 0,39 & 0,13 & 0,54 & 0,31 & 0,36 & 0,33 & 0,29 & 0,05 & 0,40 & 0,24 \\
\hline $\mathrm{MgO}$ & 29,31 & 29,45 & 29,54 & 29,96 & 29,68 & 29,12 & 26,35 & 21,53 & 25,20 & 27,18 & 25,69 & 27,42 & 26,83 & 14,84 & 16,12 & 13,50 & 13,62 & 12,67 & 12,52 \\
\hline $\mathrm{CaO}$ & 1,71 & 1,50 & 1,61 & 1,83 & 1,94 & 1,63 & 4,23 & 5,79 & 4,50 & 3,80 & 4,19 & 3,64 & 3,77 & 15,28 & 11,84 & 17,53 & 15,13 & 18,50 & 18,42 \\
\hline $\mathrm{Na} 2 \mathrm{O}$ & 0,05 & 0,07 & 0,06 & 0,08 & 0,04 & 0,02 & 0,08 & 0,10 & 0,13 & 0,09 & 0,12 & 0,09 & 0,09 & 0,33 & 0,25 & 0,36 & 0,29 & 0,50 & 0,42 \\
\hline $\mathrm{K} 2 \mathrm{O}$ & 0,00 & 0,02 & 0,01 & 0,00 & 0,00 & 0,01 & 0,02 & 0,02 & 0,09 & 0,00 & 0,01 & 0,01 & 0,00 & 0,01 & 0,02 & 0,01 & 0,02 & 0,01 & 0,00 \\
\hline Total & 99,86 & 99,61 & 100,23 & 100,45 & 100,01 & 100,06 & 100,09 & 99,56 & 99,72 & 100,01 & 100,34 & 100,37 & 99,90 & 100,71 & 100,29 & 100,34 & 100,99 & 99,45 & 99,28 \\
\hline TSi & 1,92 & 1,94 & 1,91 & 1,91 & 1,92 & 1,92 & 1,93 & 1,96 & 1,93 & 1,91 & 1,93 & 1,92 & 1,92 & 1,90 & 1,93 & 1,90 & 1,92 & 1,85 & 1,90 \\
\hline TAl & 0,08 & 0,06 & 0,09 & 0,09 & 0,08 & 0,09 & 0,07 & 0,04 & 0,07 & 0,09 & 0,07 & 0,08 & 0,08 & 0,10 & 0,07 & 0,10 & 0,08 & 0,15 & 0,11 \\
\hline TFe3+ & 0,00 & 0,00 & 0,00 & 0,00 & 0,00 & 0,00 & 0,00 & 0,00 & 0,00 & 0,00 & 0,00 & 0,00 & 0,00 & 0,00 & 0,00 & 0,00 & 0,01 & 0,00 & 0,00 \\
\hline M1Fe3+ & 0,03 & 0,02 & 0,02 & 0,06 & 0,03 & 0,01 & 0,03 & 0,00 & 0,02 & 0,05 & 0,03 & 0,02 & 0,02 & 0,05 & 0,00 & 0,02 & 0,05 & 0,04 & 0,02 \\
\hline $\mathrm{M} 1 \mathrm{Fe} 2+$ & 0,00 & 0,00 & 0,00 & 0,00 & 0,00 & 0,00 & 0,00 & 0,00 & 0,00 & 0,00 & 0,00 & 0,00 & 0,00 & 0,08 & 0,04 & 0,16 & 0,16 & 0,16 & 0,20 \\
\hline $\mathrm{M} 1 \mathrm{Cr}$ & 0,01 & 0,01 & 0,01 & 0,01 & 0,01 & 0,01 & 0,01 & 0,00 & 0,01 & 0,01 & 0,00 & 0,02 & 0,01 & 0,01 & 0,01 & 0,01 & 0,00 & 0,01 & 0,01 \\
\hline $\mathrm{M} 1 \mathrm{Mg}$ & 0,92 & 0,94 & 0,92 & 0,91 & 0,92 & 0,92 & 0,93 & 0,95 & 0,93 & 0,92 & 0,94 & 0,92 & 0,93 & 0,83 & 0,90 & 0,76 & 0,77 & 0,72 & 0,71 \\
\hline $\mathrm{M} 2 \mathrm{Mg}$ & 0,63 & 0,62 & 0,64 & 0,66 & 0,64 & 0,61 & 0,48 & 0,24 & 0,44 & 0,53 & 0,44 & 0,53 & 0,50 & 0,00 & 0,00 & 0,00 & 0,00 & 0,00 & 0,00 \\
\hline $\mathrm{M} 2 \mathrm{Fe} 2+$ & 0,30 & 0,31 & 0,30 & 0,26 & 0,28 & 0,32 & 0,35 & 0,52 & 0,37 & 0,31 & 0,38 & 0,32 & 0,34 & 0,35 & 0,49 & 0,26 & 0,36 & 0,20 & 0,21 \\
\hline $\mathrm{M} 2 \mathrm{Mn}$ & 0,01 & 0,01 & 0,00 & 0,01 & 0,01 & 0,01 & 0,01 & 0,01 & 0,01 & 0,01 & 0,01 & 0,01 & 0,01 & 0,01 & 0,01 & 0,01 & 0,01 & 0,01 & 0,01 \\
\hline $\mathrm{M} 2 \mathrm{Ca}$ & 0,07 & 0,06 & 0,06 & 0,07 & 0,07 & 0,06 & 0,16 & 0,23 & 0,17 & 0,15 & 0,16 & 0,14 & 0,15 & 0,61 & 0,48 & 0,71 & 0,61 & 0,75 & 0,75 \\
\hline $\mathrm{M} 2 \mathrm{Na}$ & 0,00 & 0,01 & 0,00 & 0,01 & 0,00 & 0,00 & 0,01 & 0,01 & 0,01 & 0,01 & 0,01 & 0,01 & 0,01 & 0,02 & 0,02 & 0,03 & 0,02 & 0,04 & 0,03 \\
\hline $\mathrm{M} 2 \mathrm{~K}$ & 0,00 & 0,00 & 0,00 & 0,00 & 0,00 & 0,00 & 0,00 & 0,00 & 0,00 & 0,00 & 0,00 & 0,00 & 0,00 & 0,00 & 0,00 & 0,00 & 0,00 & 0,00 & 0,00 \\
\hline Total & 4,00 & 4,00 & 4,00 & 4,00 & 4,00 & 4,00 & 4,00 & 4,00 & 4,00 & 4,00 & 4,00 & 4,00 & 4,00 & 4,00 & 4,00 & 4,00 & 4,00 & 4,00 & 4,00 \\
\hline Wo & 3,33 & 2,93 & 3,16 & 3,51 & 3,77 & 3,20 & 8,31 & 11,82 & 8,98 & 7,42 & 8,45 & 7,15 & 7,43 & 31,70 & 24,82 & 37,00 & 31,29 & 40,11 & 39,66 \\
\hline En & 79,51 & 79,98 & 80,43 & 79,95 & 80,23 & 79,75 & 72,04 & 61,16 & 70,80 & 73,76 & 70,41 & 74,93 & 73,59 & 42,83 & 47,03 & 39,65 & 39,19 & 38,20 & 37,51 \\
\hline Fs & 17,16 & 17,09 & 16,41 & 16,54 & 16,00 & 17,04 & 19,65 & 27,02 & 20,22 & 18,82 & 21,34 & 17,92 & 18,99 & 25,48 & 28,14 & 23,35 & 29,53 & 21,69 & 22,83 \\
\hline
\end{tabular}

da matriz. Zonamento oscilatório normal e inverso são (análises 1 e 3 da amostra CAJ-03 da Tab. 3.A). Microobservados. No primeiro caso, pequena variação para fenocristais com zonamento inverso podem apresentar teores menos cálcicos é medida em direção às bordas variações mais significativas entre centro e borda (aná- 
Tabela 3.B - Composições químicas de piroxênio (fenocristais e matriz) em amostras de diques das fazendas Cajazeiras e Maravilha.

\begin{tabular}{|c|c|c|c|c|c|c|c|c|c|c|c|c|c|c|c|c|c|c|}
\hline \multirow{2}{*}{$\begin{array}{l}\text { Dique } \\
\text { Análise }\end{array}$} & \multicolumn{6}{|c|}{ CAJ-03 } & \multicolumn{5}{|c|}{ CAJ-05 } & \multicolumn{7}{|c|}{ CAJ-10 } \\
\hline & \multirow{2}{*}{\multicolumn{2}{|c|}{$\begin{array}{c}1 \\
\text { fenocristal }\end{array}$}} & \multicolumn{2}{|c|}{2} & \multicolumn{2}{|c|}{3} & \multirow{3}{*}{$\begin{array}{c}1 \\
\text { matriz }\end{array}$} & \multirow{3}{*}{$\begin{array}{c}2 \\
\text { matriz }\end{array}$} & \multirow{3}{*}{$\begin{array}{c}3 \\
\text { matriz }\end{array}$} & \multirow{2}{*}{$\begin{array}{c}4 \\
\text { matriz }\end{array}$} & \multirow{3}{*}{$\begin{array}{c}5 \\
\text { matriz }\end{array}$} & \multirow{2}{*}{\multicolumn{2}{|c|}{$\begin{array}{c}1 \\
\text { fenocristal }\end{array}$}} & \multirow{2}{*}{\multicolumn{2}{|c|}{$\begin{array}{c}2 \\
\text { fenocristal }\end{array}$}} & \multirow{3}{*}{$\begin{array}{c}3 \\
\text { matriz }\end{array}$} & \multirow{3}{*}{$\begin{array}{c}4 \\
\text { matriz }\end{array}$} & \multirow{3}{*}{$\begin{array}{c}5 \\
\text { matriz }\end{array}$} \\
\hline & & & fenoc & ristal & fenoc & cristal & & & & & & & & & & & & \\
\hline & $n$ & $b$ & $n$ & $b$ & $n$ & $b$ & & & & & & $n$ & $b$ & $n$ & $b$ & & & \\
\hline $\mathrm{SiO} 2$ & 51,88 & 52,13 & 52,49 & 52,09 & 52,63 & 52,52 & 53,75 & 53,39 & 52,99 & 52,62 & 52,99 & 55,96 & 54,14 & 54,72 & 54,38 & 54,95 & 54,69 & 54,06 \\
\hline $\mathrm{A} 12 \mathrm{O} 3$ & 29,79 & 29,38 & 29,13 & 29,27 & 29,14 & 28,82 & 28,00 & 28,29 & 29,59 & 29,40 & 29,60 & 28,44 & 29,42 & 28,64 & 29,51 & 27,75 & 26,81 & 28,37 \\
\hline $\mathrm{TiO} 2$ & 0,09 & 0,07 & 0,14 & 0,10 & 0,08 & 0,09 & 0,10 & 0,14 & 0,10 & 0,03 & 0,11 & 0,04 & 0,00 & 0,15 & 0,09 & 0,08 & 0,26 & 0,06 \\
\hline $\mathrm{MgO}$ & 0,14 & 0,14 & 0,16 & 0,15 & 0,16 & 0,17 & 0,16 & 0,28 & 0,14 & 0,45 & 0,14 & 0,12 & 0,16 & 0,12 & 0,15 & 0,17 & 0,43 & 0,17 \\
\hline $\mathrm{Fe} 2 \mathrm{O} 3$ & 0,37 & 0,46 & 0,46 & 0,45 & 0,50 & 0,51 & 0,66 & 1,00 & 0,47 & 0,68 & 0,49 & 0,34 & 0,30 & 0,37 & 0,37 & 0,68 & 2,39 & 0,67 \\
\hline $\mathrm{MnO}$ & 0,00 & 0,00 & 0,04 & 0,00 & 0,00 & 0,01 & 0,00 & 0,10 & 0,00 & 0,01 & 0,00 & 0,03 & 0,00 & 0,00 & 0,00 & 0,00 & 0,00 & 0,02 \\
\hline $\mathrm{CaO}$ & 12,70 & 12,30 & 12,27 & 12,47 & 12,23 & 11,90 & 11,01 & 11,66 & 12,36 & 12,14 & 12,47 & 10,62 & 12,02 & 11,15 & 11,95 & 11,01 & 10,55 & 11,12 \\
\hline $\mathrm{Na} 2 \mathrm{O}$ & 4,12 & 4,37 & 4,45 & 4,26 & 4,40 & 4,61 & 5,03 & 4,69 & 4,55 & 4,37 & 4,38 & 5,29 & 4,62 & 5,05 & 4,70 & 5,45 & 5,45 & 5,34 \\
\hline $\mathrm{K} 2 \mathrm{O}$ & 0,21 & 0,24 & 0,22 & 0,21 & 0,22 & 0,22 & 0,32 & 0,26 & 0,17 & 0,19 & 0,20 & 0,17 & 0,12 & 0,14 & 0,11 & 0,21 & 0,38 & 0,16 \\
\hline Total & 99,27 & 99,10 & 99,37 & 98,99 & 99,36 & 98,87 & 99,04 & 99,82 & 100,36 & 99,89 & 100,36 & 101,00 & 100,78 & 100,34 & 101,26 & 100,28 & 100,96 & 99,97 \\
\hline An & 62,20 & 60,02 & 59,62 & 61,09 & 59,83 & 58,01 & 53,72 & 56,97 & 59,44 & 59,84 & 60,43 & 52,07 & 58,58 & 54,53 & 58,05 & 52,16 & 50,58 & 53,05 \\
\hline $\mathrm{Ab}$ & 36,56 & 38,60 & 39,13 & 37,72 & 38,90 & 40,69 & 44,40 & 41,50 & 39,57 & 39,02 & 38,44 & 46,92 & 40,72 & 44,66 & 41,31 & 46,68 & 47,25 & 46,05 \\
\hline Or & 1,24 & 1,38 & 1,26 & 1,20 & 1,27 & 1,30 & 1,88 & 1,54 & 1,00 & 1,14 & 1,13 & 1,02 & 0,71 & 0,81 & 0,64 & 1,17 & 2,17 & 0,89 \\
\hline $\mathrm{Si}$ & 9,494 & 9,554 & 9,594 & 9,557 & 9,612 & 9,641 & 9,828 & 9,715 & 9,584 & 9,564 & 9,582 & 9,979 & 9,717 & 9,848 & 9,714 & 9,918 & 9,870 & 9,797 \\
\hline $\mathrm{Al}$ & 6,418 & 6,345 & 6,275 & 6,328 & 6,272 & 6,235 & 6,034 & 6,068 & 6,307 & 6,297 & 6,309 & 5,976 & 6,222 & 6,074 & 6,214 & 5,903 & 5,701 & 6,059 \\
\hline $\mathrm{Ti}$ & 0,013 & 0,010 & 0,019 & 0,014 & 0,011 & 0,013 & 0,014 & 0,019 & 0,014 & 0,004 & 0,015 & 0,005 & 0,000 & 0,020 & 0,012 & 0,011 & 0,035 & 0,008 \\
\hline $\mathrm{Mg}$ & 0,037 & 0,039 & 0,043 & 0,040 & 0,045 & 0,047 & 0,042 & 0,077 & 0,036 & 0,122 & 0,037 & 0,033 & 0,042 & 0,031 & 0,039 & 0,044 & 0,116 & 0,045 \\
\hline $\mathrm{Fe}$ & 0,051 & 0,063 & 0,063 & 0,062 & 0,069 & 0,070 & 0,091 & 0,137 & 0,064 & 0,092 & 0,066 & 0,045 & 0,040 & 0,050 & 0,050 & 0,092 & 0,324 & 0,091 \\
\hline $\mathrm{Mn}$ & 0,000 & 0,001 & 0,007 & 0,000 & 0,000 & 0,002 & 0,000 & 0,015 & 0,000 & 0,001 & 0,000 & 0,004 & 0,001 & 0,000 & 0,000 & 0,000 & 0,001 & 0,003 \\
\hline $\mathrm{Ca}$ & 2,490 & 2,416 & 2,403 & 2,451 & 2,394 & 2,340 & 2,157 & 2,273 & 2,395 & 2,364 & 2,415 & 2,029 & 2,312 & 2,150 & 2,286 & 2,129 & 2,039 & 2,160 \\
\hline $\mathrm{Na}$ & 1,463 & 1,553 & 1,577 & 1,513 & 1,557 & 1,642 & 1,783 & 1,656 & 1,594 & 1,541 & 1,536 & 1,828 & 1,607 & 1,761 & 1,627 & 1,906 & 1,905 & 1,875 \\
\hline $\mathrm{K}$ & 0,050 & 0,055 & 0,051 & 0,048 & 0,051 & 0,052 & 0,075 & 0,061 & 0,040 & 0,045 & 0,045 & 0,040 & 0,028 & 0,032 & 0,025 & 0,048 & 0,087 & 0,036 \\
\hline Total & 20,016 & 20,036 & 20,031 & 20,015 & 20,010 & 20,041 & 20,025 & 20,022 & 20,034 & 20,030 & 20,006 & 19,938 & 19,969 & 19,966 & 19,968 & 20,051 & 20,079 & 20,075 \\
\hline
\end{tabular}

* os valores dos óxidos e teores de Wo(wollastonita), En(enstatita) e Fe(ferrosilita) são dados em percentagem. Legenda: $n=$ núcleo/ centro; $b=$ borda.

lise 2/CAJ-03 e análises 1 e 2 da amostra CAJ-10 da Tab. 3.A). Eventualmente é possível observar cristais com textura de desequilíbrio tipo sieve, cujas cavidades interconectadas preenchidas por vidro criptocristalino, substituído por material de alteração, estão restritas às partes centrais do cristal (Fig. 3.B).

Microfenocristais de clinopiroxênio têm variação composicional insignificante entre núcleo e borda
$\left(\mathrm{Wo}_{40-46} \mathrm{En}_{36-42} \mathrm{Fs}_{16-19}\right)$ associada a altos teores de $\mathrm{Al}_{2} \mathrm{O}_{3}$ $(5,2-6,2 \%))^{-2} \mathrm{TiO}_{2}(1,5-3,2 \%)$ (Fig. 5.A), semelhantes àqueles da matriz. Zonamento oscilatório marcante $\mathrm{e}$ variações composicionais significativas não foram observados nas seções investigadas, muito embora teores ligeiramente menos cálcicos tenham sido medidos nas bordas de microfenocristais. Condições de cristalização em equilíbrio com plagioclásio e olivina são evidencia- 
Tabela 3.B - Continuação

\begin{tabular}{|c|c|c|c|c|c|c|c|c|c|c|c|c|c|c|c|}
\hline \multirow{2}{*}{$\begin{array}{l}\text { Dique } \\
\text { Análise }\end{array}$} & \multicolumn{3}{|c|}{ CAJ-15 } & \multicolumn{6}{|c|}{ MR-04 } & \multicolumn{6}{|c|}{ MR-08 } \\
\hline & 1 & & & \multicolumn{2}{|c|}{1} & \multicolumn{2}{|c|}{2} & \multicolumn{2}{|c|}{3} & \multicolumn{2}{|c|}{1} & \multicolumn{2}{|c|}{2} & \multicolumn{2}{|c|}{3} \\
\hline & matriz & matriz & matriz & \multicolumn{2}{|c|}{ cristal } & \multicolumn{2}{|c|}{ cristal } & \multicolumn{2}{|c|}{ cristal } & \multicolumn{2}{|c|}{ cristal } & \multicolumn{2}{|c|}{ cristal } & \multicolumn{2}{|c|}{ cristal } \\
\hline & & & & $n$ & $b$ & $n$ & $b$ & $n$ & $b$ & $n$ & $b$ & $n$ & $b$ & $n$ & $b$ \\
\hline $\mathrm{SiO} 2$ & 54,41 & 56,14 & 54,71 & 54,68 & 54,78 & 56,02 & 58,05 & 54,63 & 59,02 & 58,40 & 61,43 & 55,41 & 58,71 & 55,90 & 57,84 \\
\hline $\mathrm{A} 12 \mathrm{O} 3$ & 27,40 & 26,58 & 27,78 & 28,45 & 28,45 & 27,77 & 25,74 & 28,06 & 25,01 & 26,07 & 22,43 & 28,00 & 25,56 & 27,73 & 26,03 \\
\hline $\mathrm{TiO} 2$ & 0,05 & 0,12 & 0,11 & 0,04 & 0,00 & 0,08 & 0,16 & 0,13 & 0,11 & 0,09 & 0,03 & 0,07 & 0,09 & 0,09 & 0,02 \\
\hline $\mathrm{MgO}$ & 0,27 & 0,15 & 0,33 & 0,13 & 0,18 & 0,13 & 0,10 & 0,14 & 0,08 & 0,10 & 0,88 & 0,16 & 0,16 & 0,13 & 0,15 \\
\hline $\mathrm{Fe} 2 \mathrm{O} 3$ & 1,03 & 0,71 & 1,16 & 0,34 & 0,43 & 0,45 & 0,70 & 0,39 & 0,58 & 0,61 & 1,85 & 0,44 & 0,67 & 0,26 & 0,68 \\
\hline $\mathrm{MnO}$ & 0,00 & 0,01 & 0,00 & 0,00 & 0,01 & 0,00 & 0,02 & 0,02 & 0,02 & 0,00 & 0,00 & 0,05 & 0,02 & 0,03 & 0,03 \\
\hline $\mathrm{CaO}$ & 10,35 & 9,78 & 10,53 & 11,24 & 11,51 & 10,35 & 8,17 & 11,13 & 7,50 & 8,51 & 4,88 & 10,56 & 8,20 & 10,25 & 8,79 \\
\hline $\mathrm{Na} 2 \mathrm{O}$ & 5,45 & 5,91 & 5,48 & 5,28 & 5,19 & 5,81 & 6,96 & 5,36 & 7,39 & 6,59 & 7,94 & 5,26 & 6,71 & 5,61 & 6,54 \\
\hline $\mathrm{K} 2 \mathrm{O}$ & 0,20 & 0,23 & 0,17 & 0,08 & 0,09 & 0,13 & 0,20 & 0,09 & 0,23 & 0,19 & 0,42 & 0,10 & 0,24 & 0,10 & 0,20 \\
\hline Total & 99,16 & 99,62 & 100,25 & 100,24 & 100,63 & 100,72 & 100,09 & 99,96 & 99,93 & 100,56 & 99,86 & 100,04 & 100,35 & 100,09 & 100,27 \\
\hline An & 50,61 & 47,15 & 51,02 & 53,80 & 54,77 & 49,23 & 38,92 & 53,17 & 35,44 & 41,18 & 24,70 & 52,26 & 39,77 & 49,95 & 42,16 \\
\hline $\mathrm{Ab}$ & 48,22 & 51,54 & 48,03 & 45,73 & 44,73 & 50,05 & 59,95 & 46,33 & 63,27 & 57,74 & 72,79 & 47,13 & 58,86 & 49,47 & 56,72 \\
\hline Or & 1,18 & 1,30 & 0,96 & 0,47 & 0,50 & 0,73 & 1,13 & 0,50 & 1,28 & 1,08 & 2,51 & 0,61 & 1,37 & 0,59 & 1,12 \\
\hline $\mathrm{Si}$ & 9,928 & 1,159 & 9,881 & 9,858 & 9,846 & 10,029 & 10,412 & 9,881 & 10,578 & 10,412 & 10,973 & 9,980 & 10,485 & 10,052 & 10,362 \\
\hline $\mathrm{Al}$ & 5,891 & 5,670 & 5,913 & 6,045 & 6,026 & 5,859 & 5,441 & 5,982 & 5,283 & 5,478 & 4,721 & 5,944 & 5,379 & 5,876 & 5,496 \\
\hline $\mathrm{Ti}$ & 0,007 & 0,016 & 0,015 & 0,005 & 0,000 & 0,011 & 0,022 & 0,018 & 0,015 & 0,012 & 0,004 & 0,009 & 0,012 & 0,012 & 0,003 \\
\hline $\mathrm{Mg}$ & 0,074 & 0,040 & 0,088 & 0,036 & 0,049 & 0,034 & 0,026 & 0,039 & 0,020 & 0,027 & 0,235 & 0,042 & 0,044 & 0,035 & 0,041 \\
\hline $\mathrm{Fe}$ & 0,141 & 0,097 & 0,157 & 0,045 & 0,058 & 0,060 & 0,094 & 0,053 & 0,078 & 0,081 & 0,249 & 0,059 & 0,090 & 0,036 & 0,092 \\
\hline $\mathrm{Mn}$ & 0,000 & 0,001 & 0,000 & 0,000 & 0,001 & 0,000 & 0,002 & 0,004 & 0,003 & 0,000 & 0,001 & 0,007 & 0,002 & 0,004 & 0,004 \\
\hline $\mathrm{Ca}$ & 2,022 & 1,896 & 2,037 & 2,171 & 2,216 & 1,985 & 1,570 & 2,157 & 1,439 & 1,625 & 0,934 & 2,037 & 1,569 & 1,975 & 1,687 \\
\hline $\mathrm{Na}$ & 1,927 & 2,072 & 1,917 & 1,845 & 1,810 & 2,018 & 2,419 & 1,879 & 2,569 & 2,279 & 2,751 & 1,837 & 2,321 & 1,976 & 2,270 \\
\hline $\mathrm{K}$ & 0,047 & 0,052 & 0,038 & 0,019 & 0,020 & 0,029 & 0,046 & 0,020 & 0,052 & 0,043 & 0,095 & 0,024 & 0,054 & 0,023 & 0,045 \\
\hline Total & 20,037 & 20,003 & 20,047 & 20,024 & 20,027 & 20,024 & 20,032 & 20,033 & 20,037 & 19,957 & 19,961 & 19,939 & 19,956 & 19,969 & 19,999 \\
\hline
\end{tabular}

das por contatos retos (Fig. 3.C), especialmente ilustrados onde o agrupamento dos cristais define textura glomeroporfirítica (Fig. 3.D). O conteúdo de forsterita (Fo) das olivinas é pouco variável entre bordas e núcleos $\left(\mathrm{Fo}_{81-84}\right)$; micro-inclusões de cromoespinélio analisadas por $\operatorname{EDS}\left(\mathrm{Cr}_{2} \mathrm{O}_{3} 31,6-33,6 \%, \mathrm{Al}_{2} \mathrm{O}_{3} 22-25 \%\right)$ são freqüentes nesta fase mineral. Evidências texturais de mistura de magmas ou assimilação (crustal), como por exemplo assembléias de fenocristais em desequilíbrio ou presença de xenocristais, não foram observadas.
Diques contendo microfenocristais de olivina Este grupo inclui parte dos diques máficos que ocorrem na Fazenda Cajazeiras, os quais são petrograficamente distintos daqueles do grupo anterior, descrito acima. Compreende os diques CAJ-08, CAJ-11 a -17 e CAJ20. Apresentam matriz inequigranular muito fina a fina $(0,05$ a $0,8 \mathrm{~mm})$, dominantemente constituída por cristais euédricos a subeuédricos de plagioclásio e clinopiroxênio e, em menor proporção, olivina; vidro e óxidos de Fe-Mg-Ti ocorrem nos interstícios entre esses 
Tabela 3.C - Composições químicas de olivina em amostras de diques das fazendas Cajazeiras e Maravilha. * os valores dos óxidos e teores de Fo(forsterita) e Fa(fayalita) são dados em percentagem.

\begin{tabular}{|c|c|c|c|c|c|c|c|c|c|c|c|c|c|}
\hline \multirow{2}{*}{$\begin{array}{l}\text { Dique } \\
\text { Análise }\end{array}$} & \multicolumn{2}{|c|}{ CAJ-03 } & \multicolumn{3}{|c|}{ CAJ-05 } & \multicolumn{2}{|c|}{ CAJ-15 } & \multicolumn{4}{|c|}{ MR-04 } & \multicolumn{2}{|c|}{ MR-08 } \\
\hline & $\begin{array}{c}1 \\
\text { feno- } \\
\text { cristal }\end{array}$ & $\begin{array}{c}2 \\
\text { feno- } \\
\text { cristal }\end{array}$ & $\begin{array}{c}1 \\
\text { feno- } \\
\text { cristal }\end{array}$ & $\begin{array}{c}2 \\
\text { fenocristal }\end{array}$ & $\begin{array}{c}3 \\
\text { feno- } \\
\text { cristal }\end{array}$ & $\begin{array}{c}1 \\
\text { feno- } \\
\text { cristal }\end{array}$ & $\begin{array}{c}2 \\
\text { feno- } \\
\text { cristal }\end{array}$ & $\begin{array}{c}1 \\
\text { feno- } \\
\text { cristal }\end{array}$ & $\begin{array}{c}2 \\
\text { feno- } \\
\text { cristal }\end{array}$ & $\begin{array}{c}3 \\
\text { feno- } \\
\text { cristal }\end{array}$ & $\begin{array}{c}4 \\
\text { feno- } \\
\text { cristal }\end{array}$ & $\begin{array}{c}1 \\
\text { feno- } \\
\text { cristal }\end{array}$ & $\begin{array}{c}2 \\
\text { feno- } \\
\text { cristal }\end{array}$ \\
\hline $\mathrm{SiO} 2$ & 38,76 & 39,18 & 39,83 & 39,71 & 40,16 & 38,98 & 39,23 & 39,05 & 38,30 & 38,93 & 38,57 & 39,22 & 37,65 \\
\hline A12O3 & 0,07 & 0,06 & 0,07 & 0,06 & 0,11 & 0,03 & 0,03 & 0,08 & 0,04 & 0,06 & 0,05 & 0,02 & 0,02 \\
\hline $\mathrm{TiO} 2$ & 0,00 & 0,01 & 0,05 & 0,11 & 0,06 & 0,02 & 0,04 & 0,04 & 0,06 & 0,05 & 0,08 & 0,00 & 0,05 \\
\hline $\mathrm{MgO}$ & 43,29 & 43,81 & 44,47 & 42,87 & 43,29 & 43,28 & 43,00 & 39,66 & 40,91 & 40,62 & 39,23 & 39,87 & 35,95 \\
\hline $\mathrm{FeO}$ & 16,30 & 15,74 & 14,75 & 17,52 & 15,75 & 17,30 & 17,49 & 21,54 & 19,81 & 20,82 & 22,30 & 19,94 & 25,45 \\
\hline $\mathrm{MnO}$ & 0,20 & 0,21 & 0,18 & 0,22 & 0,17 & 0,21 & 0,17 & 0,25 & 0,24 & 0,18 & 0,14 & 0,24 & 0,33 \\
\hline $\mathrm{CaO}$ & 0,22 & 0,22 & 0,23 & 0,25 & 0,18 & 0,22 & 0,25 & 0,27 & 0,21 & 0,20 & 0,19 & 0,20 & 0,27 \\
\hline $\mathrm{Cr} 2 \mathrm{O} 3$ & 0,05 & 0,04 & 0,06 & 0,05 & 0,05 & 0,05 & 0,07 & 0,07 & 0,05 & 0,04 & 0,06 & 0,03 & 0,05 \\
\hline $\mathrm{Na} 2 \mathrm{O}$ & 0,02 & 0,01 & 0,02 & 0,01 & 0,02 & 0,00 & 0,02 & 0,01 & 0,01 & 0,02 & 0,01 & 0,00 & 0,01 \\
\hline $\mathrm{K} 2 \mathrm{O}$ & 0,00 & 0,00 & 0,02 & 0,00 & 0,00 & 0,00 & 0,01 & 0,02 & 0,00 & 0,00 & 0,01 & 0,00 & 0,01 \\
\hline $\mathrm{NiO}$ & 0,23 & 0,31 & 0,31 & 0,22 & 0,25 & 0,25 & 0,24 & 0,13 & 0,20 & 0,16 & 0,18 & 0,19 & 0,18 \\
\hline Total & 99,14 & 99,56 & 99,98 & 101,02 & 100,03 & 100,32 & 100,53 & 101,11 & 99,82 & 101,08 & 100,82 & 99,71 & 99,97 \\
\hline Fo & 82,57 & 83,23 & 84,31 & 81,36 & 83,06 & 81,69 & 81,42 & 76,66 & 78,64 & 77,67 & 75,82 & 78,10 & 71,58 \\
\hline $\mathrm{Fa}$ & 17,43 & 16,77 & 15,69 & 18,64 & 16,94 & 18,31 & 18,58 & 23,34 & 21,36 & 22,33 & 24,18 & 21,90 & 28,42 \\
\hline $\mathrm{Si}$ & 0,991 & 0,994 & 1,001 & 0,999 & 1,011 & 0,989 & 0,993 & 1,000 & 0,989 & 0,995 & 0,995 & 1,011 & 0,997 \\
\hline $\mathrm{Al}$ & 0,002 & 0,002 & 0,002 & 0,002 & 0,003 & 0,001 & 0,001 & 0,003 & 0,001 & 0,002 & 0,002 & 0,001 & 0,001 \\
\hline $\mathrm{Ti}$ & 0,000 & 0,000 & 0,001 & 0,002 & 0,001 & 0,000 & 0,001 & 0,001 & 0,001 & 0,001 & 0,001 & 0,000 & 0,001 \\
\hline $\mathrm{Mg}$ & 1,650 & 1,657 & 1,665 & 1,608 & 1,624 & 1,637 & 1,623 & 1,515 & 1,574 & 1,547 & 1,509 & 1,532 & 1,419 \\
\hline $\mathrm{Fe}$ & 0,348 & 0,334 & 0,310 & 0,369 & 0,331 & 0,367 & 0,370 & 0,461 & 0,428 & 0,445 & 0,481 & 0,430 & 0,564 \\
\hline $\mathrm{Mn}$ & 0,004 & 0,004 & 0,004 & 0,005 & 0,004 & 0,004 & 0,004 & 0,005 & 0,005 & 0,004 & 0,003 & 0,005 & 0,007 \\
\hline $\mathrm{Ca}$ & 0,006 & 0,006 & 0,006 & 0,007 & 0,005 & 0,006 & 0,007 & 0,007 & 0,006 & 0,006 & 0,005 & 0,006 & 0,008 \\
\hline $\mathrm{Cr}$ & 0,001 & 0,001 & 0,001 & 0,001 & 0,001 & 0,001 & 0,001 & 0,001 & 0,001 & 0,001 & 0,001 & 0,001 & 0,001 \\
\hline $\mathrm{Na}$ & 0,001 & 0,000 & 0,001 & 0,001 & 0,001 & 0,000 & 0,001 & 0,001 & 0,000 & 0,001 & 0,000 & 0,000 & 0,001 \\
\hline K & 0,000 & 0,000 & 0,001 & 0,000 & 0,000 & 0,000 & 0,000 & 0,000 & 0,000 & 0,000 & 0,000 & 0,000 & 0,000 \\
\hline $\mathrm{Ni}$ & 0,005 & 0,006 & 0,006 & 0,004 & 0,005 & 0,005 & 0,005 & 0,003 & 0,004 & 0,003 & 0,004 & 0,004 & 0,004 \\
\hline Total & 3,008 & 3,005 & 2,998 & 2,998 & 2,987 & 3,010 & 3,005 & 2,998 & 3,009 & 3,004 & 3,002 & 2,989 & 3,002 \\
\hline
\end{tabular}

* os valores dos óxidos e teores de Fo(forsterita) e Fa(fayalita) são dados em percentagem.

cristais. A textura geral da matriz é intergranular-intersertal. Micrólitos de plagioclásio têm $\mathrm{An}_{47-51}$ (andesinalabradorita) (Fig. 4.C) e, como nos diques anteriores, podem apresentar morfologia textural tipo swallowtail. O clinopiroxênio, na matriz, tem composição $\mathrm{Wo}_{6-}$
${ }_{13} \mathrm{En}_{61-76} \mathrm{Fs}_{18-27}$ (Fig. 5.B). Os altos teores de magnésio $(>20 \%)$ associados com concentrações sub-cálcicas (3-7\%) indicam composição de pigeonita magnesiana. O dique CAJ-15 apresenta pequenos aglomerados de microfenocristais de ortopiroxênio $\left(\mathrm{Wo}_{3-4} \mathrm{En}_{79-81} \mathrm{Fs}_{16-17}\right)$ 
Tabela 3.D - Composições químicas de carbonato (intersticial e amígdala) em amostras de diques das fazendas Cajazeiras e Maravilha.

\begin{tabular}{|c|c|c|c|c|c|c|c|c|c|c|c|}
\hline \multirow{2}{*}{$\begin{array}{l}\text { Dique } \\
\text { Análise }\end{array}$} & \multicolumn{4}{|c|}{ CAJ-03 } & \multicolumn{3}{|c|}{ CAJ-15 } & \multicolumn{4}{|c|}{ MR-04 } \\
\hline & 1 & 2 & 3 & 4 & 1 & 2 & 3 & 1 & 2 & 3 & 4 \\
\hline & amig & amig & interst & interst & amig & amig & interst & amig & amig & amig & interst \\
\hline $\mathrm{SiO} 2$ & 0,00 & 0,02 & 0,43 & 0,22 & 0,01 & 0,00 & 0,02 & 0,04 & 1,63 & 0,11 & 0,14 \\
\hline $\mathrm{FeO}$ & 20,71 & 19,72 & 16,12 & 21,87 & 16,60 & 21,06 & 3,34 & 12,21 & 10,80 & 14,12 & 16,19 \\
\hline $\mathrm{MnO}$ & 0,89 & 0,44 & 0,49 & 1,98 & 0,79 & 0,78 & 0,79 & 0,34 & 0,33 & 0,63 & 0,55 \\
\hline $\mathrm{MgO}$ & 6,29 & 7,53 & 8,38 & 3,51 & 9,93 & 6,12 & 0,75 & 13,82 & 14,48 & 11,76 & 8,61 \\
\hline $\mathrm{CaO}$ & 25,57 & 25,72 & 27,96 & 25,95 & 27,26 & 26,86 & 49,54 & 27,57 & 27,06 & 27,38 & 28,69 \\
\hline $\mathrm{SrO}$ & 0,00 & 0,02 & 0,00 & 0,00 & 0,00 & 0,01 & 0,00 & 0,00 & 0,01 & 0,01 & 0,00 \\
\hline $\mathrm{BaO}$ & 0,00 & 0,00 & 0,04 & 0,00 & 0,11 & 0,00 & 0,00 & 0,02 & 0,02 & 0,04 & 0,00 \\
\hline Total & 53,46 & 53,43 & 53,41 & 53,53 & 54,70 & 54,82 & 54,43 & 54,00 & 54,32 & 54,05 & 54,18 \\
\hline $\mathrm{Si}$ & 0,000 & 0,002 & 0,045 & 0,025 & 0,001 & 0,000 & 0,002 & 0,004 & 0,155 & 0,011 & 0,015 \\
\hline $\mathrm{Fe}$ & 1,895 & 1,777 & 1,414 & 2,054 & 1,421 & 1,881 & 0,290 & 1,009 & 0,858 & 1,192 & 1,404 \\
\hline $\mathrm{Mn}$ & 0,083 & 0,040 & 0,044 & 0,188 & 0,068 & 0,070 & 0,070 & 0,028 & 0,027 & 0,053 & 0,049 \\
\hline $\mathrm{Mg}$ & 1,025 & 1,209 & 1,310 & 0,587 & 1,515 & 0,975 & 0,116 & 2,035 & 2,050 & 1,770 & 1,331 \\
\hline $\mathrm{Ca}$ & 2,997 & 2,969 & 3,142 & 3,122 & 2,990 & 3,073 & 5,521 & 2,919 & 2,754 & 2,961 & 3,187 \\
\hline $\mathrm{Sr}$ & 0,000 & 0,001 & 0,000 & 0,000 & 0,000 & 0,001 & 0,000 & 0,000 & 0,000 & 0,001 & 0,000 \\
\hline $\mathrm{Ba}$ & 0,000 & 0,000 & 0,001 & 0,000 & 0,005 & 0,000 & 0,000 & 0,001 & 0,001 & 0,002 & 0,000 \\
\hline Total & 6,000 & 5,998 & 5,955 & 5,975 & 5,999 & 6,000 & 5,998 & 5,996 & 5,845 & 5,989 & 5,985 \\
\hline
\end{tabular}

* os valores dos óxidos são dados em percentagem.

(Fig. 5.C), com $\# \mathrm{Mg}\left(100 \mathrm{Mg} / \mathrm{Mg}+\mathrm{Fe}^{2+}+\mathrm{Fe}^{3+}+\mathrm{Mn}\right)$ de $\sim 82-83$, coexistindo com microfenocristais de olivina $\left(\mathrm{Fo}_{81-82}\right)$. A incompatibilidade química entre as composições desse ortopiroxênio e do clinopiroxênio da matriz sugere que os cristais de ortopiroxênio nesta amostra podem, na verdade, tratar-se de xenocristais.

Diques faneríticos Este grupo inclui todos os diques máficos que ocorrem na Fazenda Maravilha (MR-01 a -08), excetuando os diques MR-02 e -06 que não foram incluídos neste estudo. Distinguem-se dos demais por mostrarem textura mais grossa, fanerítica fina. Plagioclásio constitui a fase mineral dominante, por vezes apresentando geminação polissintética. Cristais euédricos a subeuédricos de olivina, piroxênio, óxidos de Fe-Ti-Mg e, em menor proporção, vidro (material devitrificado) ocorre preenchendo os interstícios entre os micrólitos de plagioclásio. Esses têm composição labradorítica, com $\mathrm{An}_{\text {41-53/núcleo }}$ e $\mathrm{An}_{25-49 \text { borda }}$ (Fig. 4.D). Piroxênio nesses diques tem composição relativamente heterogênea quando comparado aos piroxênios dos demais grupos; apresentam alto $\mathrm{TiO}_{2}(0,91-1,52 \%)$ associado à composições titano-augíticas - $\mathrm{Wo}_{25-40} \mathrm{En}_{38 \text { - }}$
${ }_{47} \mathrm{Fs}_{22-30}$ (Fig. 5.D). Olivina mostra composições menos magnesianas $\left(\mathrm{Fo}_{72-79}\right)$ quando comparada às olivinas presentes nos outros grupos.

Feições de alteração mineralógica observadas Alterações mineralógicas são pervasivas em todo o conjunto de amostras investigado. Como evidências observamse: (i) alteração comum e, em algumas amostras, intensa da matriz e de microfenocristais de olivina ( \pm piroxênio) para iddingsita/bowlingita e (ii) a presença de carbonato (siderita) intersticial ou preenchendo microvenulações e amígdalas (Figs. 3.E e 3.F); quartzo também pode ocorrer como fase tardia. Tais feições texturais sugerem que $\mathrm{H}_{2} \mathrm{O}$ (alteração de olivina, piroxênio, matriz) e $\mathrm{CO}_{2}$ (formação de siderita) estiveram presentes na história de cristalização/resfriamento magmática, interagindo com as fases minerais primárias. Estudos microscópicos mais detalhados poderiam indicar se o processo ocorreu em sistema aberto, resultante da interação com fluidos externos (hidrotermalismo ou alteração supergênica) ou em sistema fechado, provavelmente refletindo algum processo autometassomático promovido por fluidos magmáticos ricos em $\mathrm{H}_{2} \mathrm{O}+\mathrm{CO}_{2}$. A ausência de feições 


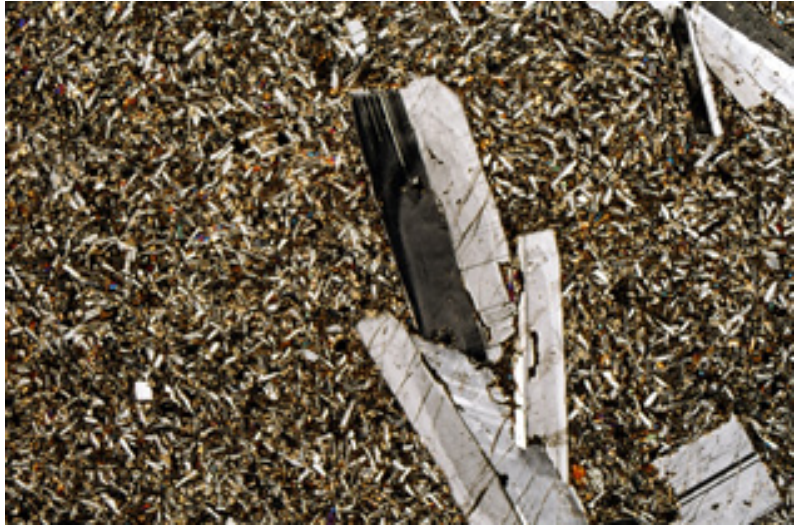

(A)

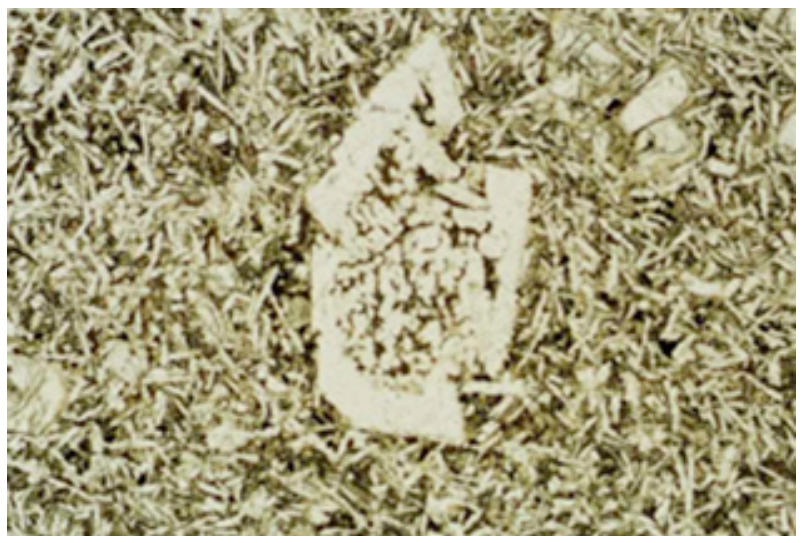

(B)

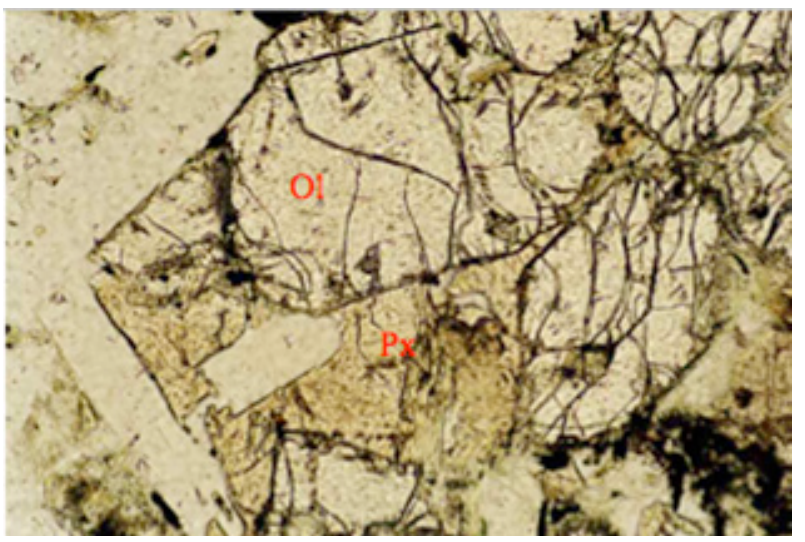

(C)

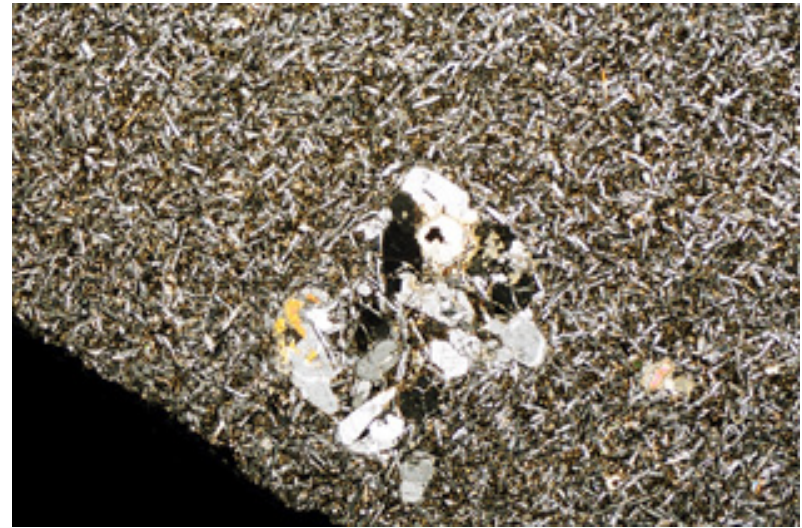

(D)

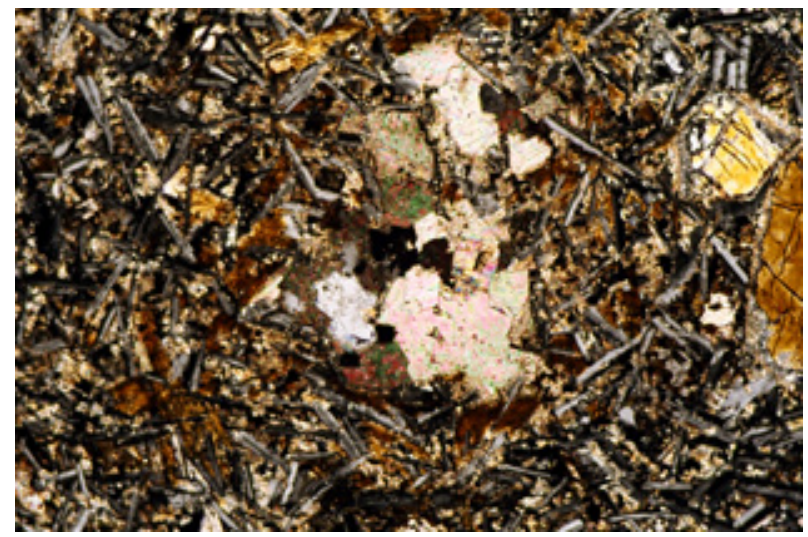

(E)

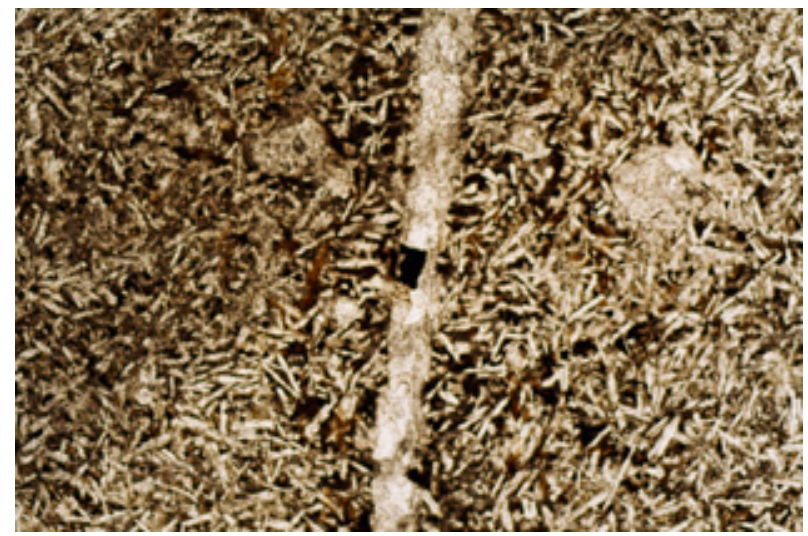

(F)

Figura 3 - Fotomicrografias de algumas texturas observadas nas seções delgadas estudadas.

A. Microfenocristais de plagioclásio zonados, imersos em matriz traquitica. (lâmina CAJ-10; nicóis cruzados; objetiva 2,5X.

B. Microfenocristal de plagioclásio apresentando textura tipo peneira (sieve). (lâmina CAJ-03; nicóis paralelos; objetiva $5 X$ ).

C. Microfenocristal de clinopiroxênio (Cpx) em contato reto com olivina (Ol). (lâmina CAJ-05; nicóis cruzados; objetiva 20X).

D. Textura glomeroporfiritica definida por microfenocristais de plagioclásio e piroxênio. (lâmina CAJ15; nicóis cruzados; objetiva 2,5X).

E. Amígdala preenchida por carbonato, com evidências de alteração mineralógica de piroxênio e opacos na matriz. (lâmina CAJ-03; nicóis cruzados; objetiva 20X).

F. Vênula preenchida por carbonato e quartzo. (lâmina CAJ-02; nicóis paralelos; objetiva 2,5X). 


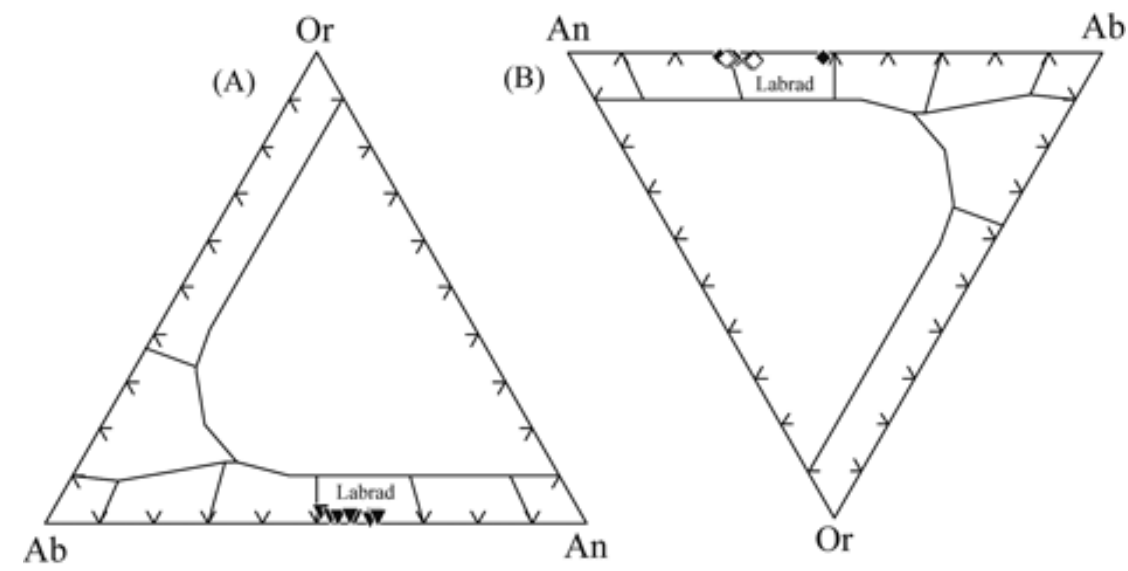

$\mathrm{Ab}$

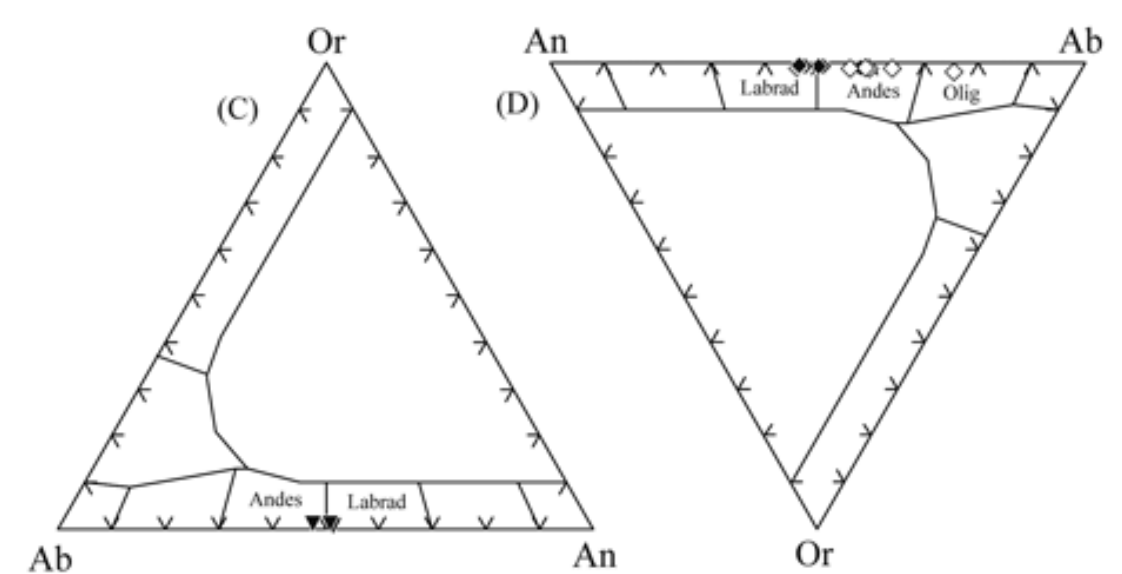

Figura 4 - Diagrama de classificação de plagioclásio para os diques máficos das fazendas Cajazeiras e Maravilha.

Legenda: Análises em: (A) micrólitos da matriz e (B) microfenocristais dos diques contendo $\mathrm{Pl}+\mathrm{Ol} \pm \mathrm{Cpx}$; (C) micrólitos da matriz dos diques com olivina; (D) cristais dos diques faneríticos. Notar que, em B) e D) os símbolos cheios são análises em núcleos/centros, enquanto os vazios representam análises em bordas.

de alteração, seja textural seja mineralógica, nas rochas encaixantes imediatamente em contato com os diques sugere, ao menos preliminarmente, que fluidos externos ao sistema magmático podem não ter sido os responsáveis por essas modificações.

O elevado grau de alteração mineralógica certamente influencia na composição química dos diques. Os altos valores de 'perda ao fogo' medidos (em geral acima de $1,5 \%$, sendo maior que $3 \%$ em seis das amostras estudadas; vide a seguir) podem ser usados como indicação do grau de alteração, sendo que valores mais elevados seriam obtidos nas amostras mais alteradas, reduzindo drasticamente a proporção real dos óxidos e inviabilizando a definição precisa da assinatura e filiação geoquímica desses magmas.

LITOQUíMICA Para o estudo litoquímico foram selecionadas amostras dos três grupos de diques, muito embora devido ao acervo relativamente pequeno não tenha sido possível excluir totalmente amostras com valores elevados de "perda ao fogo" (>2\%). Um con- junto de 10 (dez) amostras foi submetido à análise litoquímica para elementos maiores (na forma de óxidos de $\mathrm{Si}, \mathrm{Al}, \mathrm{Mn}, \mathrm{Mg}, \mathrm{Ca}, \mathrm{Na}, \mathrm{K}, \mathrm{Ti}, \mathrm{P}$ e Fe) e elementos traços (incluindo elementos terras-raras) mais comuns. Os resultados analíticos são apresentados na tabela 4. As determinações para elementos maiores foram efetuadas por Fluorescência de Raios-X, em laboratório do Instituto de Geociências da USP. A preparação das amostras envolveu a fusão de uma grama de material pulverizado (<300 mesh) com cinco gramas de uma mistura de metaborato de lítio:tetraborato de lítio na proporção 4:1, para formar uma pastilha de vidro. As condições analíticas incluíram (i) voltagem de aceleração entre $22 \mathrm{kV}$ (para $\mathrm{Al}, \mathrm{Ca}, \mathrm{Fe}, \mathrm{K}, \mathrm{Mg}, \mathrm{Na}, \mathrm{P}, \mathrm{Si}$ ) e $40 \mathrm{kV}$ (para Mn, Ti), (ii) intensidade do feixe de raio- $\mathrm{X}$ de $50 \mathrm{~mA}$, (iii) tempo médio de contagem entre 30 segundos (para Al, $\mathrm{Ca}, \mathrm{Fe}, \mathrm{K}, \mathrm{Si}$ ) e 60 segundos (para $\mathrm{Mg}, \mathrm{Na}, \mathrm{P}$ ), e (iv) correções de matriz Alpha. Maiores detalhes sobre o procedimento analítico e condições instrumentais estão descritos em Mori et al. (1999). As concentrações de elementos traços foram dosadas por espectrometria de 

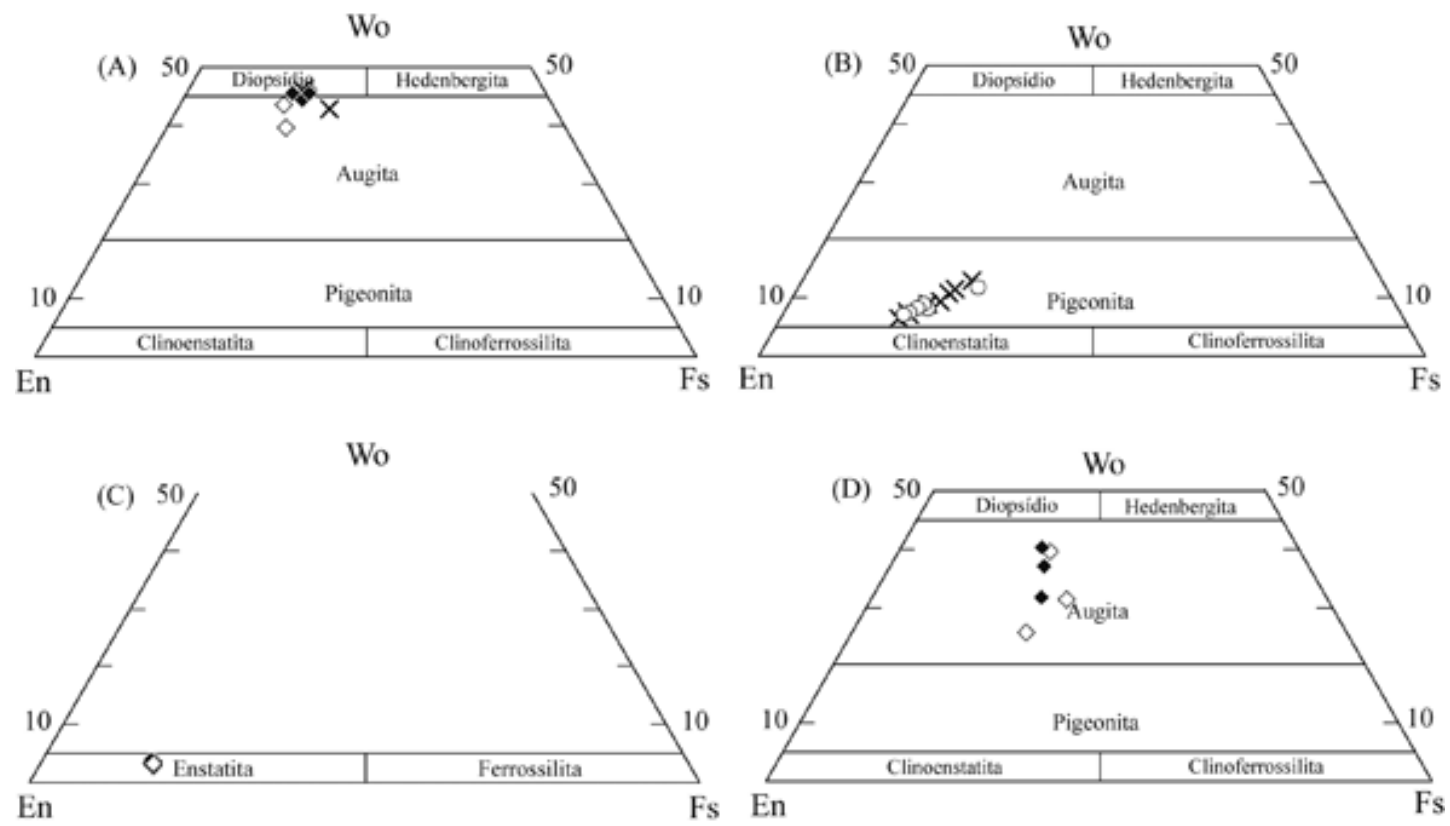

Figura 5 - Diagramas de classificação de piroxênios para os diques máficos das fazendas Cajazeiras e Maravilha.

Legenda: Análises em: (A) cristais da matriz (X) e microfenocristais (símbolo cheio - núcleo/ centro, vazio - borda) dos diques contendo $\mathrm{Pl}+\mathrm{Ol} \pm \mathrm{Cpx}$; (B) cristais de cpx da matriz e (C) microfenocristais de opx, ambos dos diques com olivina; (D) cristais (símbolo cheio - núcleo/ centro, vazio - borda) dos diques faneríticos.

massa com plasma indutivamente acoplado (ICP-MS), no Acme Analytical Laboratories, Canadá.

Para tratamento dos dados e elaboração de diagramas de classificação e variação química, e discriminantes geoquímicos foram utilizados os softwares Excel e Minpet 2.0. Para facilitar comparações entre as amostras, e considerando os elevados valores de 'perda ao fogo' (LOI) medidos, as análises de elementos maiores (óxidos) foram recalculadas para uma base livre de voláteis (segundo parâmetros de Irvine e Baragar 1971), totalizando 100\%. Os valores recalculados são também apresentados na tabela 4, sendo estes os dados analíticos plotados nos diagramas e discutidos nos itens a seguir.

Geoquímica de elementos maiores A existência de variação composicional dentro do grupo de amostras analisadas é clara quando são plotados os resultados litoquímicos em diagramas de variação tipo Harker. A distinção é especialmente observada em termos do conteúdo de sílica, o que condiciona a individualização de grupos (ou amostras) ao longo do que seria, a priori, uma tendência de fracionamento mineral desde uma composição mais primitiva $\left(\mathrm{SiO}_{2}<48 \%\right.$; dique CAJ-19), até composições mais saturadas $\left(\mathrm{SiO}_{2}>55 \%\right.$; dique MR-08). Todavia, deve-se considerar a possibilidade de que o teor de óxidos medido nas amostras não seja de todo real, principalmente naquelas com LOI > $3 \%$ (basaltos e andesito), podendo ter sido subestimado devido à presença significativa de carbonato e minerais secundários, de alteração. Devido à impossibilidade em estimar o quanto o teor original foi alterado, utilizamos os valores recalculados em base anidra para a classificação geoquímica. As relação entre proporções de álcalis versus sílica (Fig. 6) levou à individualização de basaltos $\left(\mathrm{SiO}_{2} 47-51 \%\right)$, basaltos andesíticos $\left(\mathrm{SiO}_{2}\right.$ $53-54 \%$ ) e andesito $\left(\mathrm{SiO}_{2}>55 \%\right)$.

Em termos de afinidade geoquímica, somente o dique CAJ-19 apresenta afinidade alcalina, como comprovada pela presença de nefelina (também albita) normativa $(\mathrm{Ne} 5,78)$, muito embora fases minerais sódicas não tenham sido observadas na moda. Os demais diques são sub-alcalinos, super-saturados, com afinidade toleítica (Fig. 7), também evidenciada pela presença de hiperstênio $(\mathrm{Hy})$ normativo (concentrações variando entre $11-23 \%)$. A presença de quartzo $(Q)$ ou olivina $(O l)$ normativos permite individualizar um grupo mais evoluído constituído por quartzo-toleítos ( $Q$ entre 2,1$7,8 \%$ ) e outro mais primitivo, constituído por olivinatoleítos ( $\mathrm{Ol}$ entre 3,2-5,9\%).

De forma geral, $\mathrm{CaO}, \mathrm{MgO}, \mathrm{Fe}_{2} \mathrm{O}_{3}, \mathrm{TiO}_{2}$ e $\mathrm{P}_{2} \mathrm{O}_{5}$ mostram correlação negativa com respeito à saturação em sílica (Fig. 8). Decréscimo em $\mathrm{CaO}$ combinado com aumento progressivo de $\mathrm{Na}_{2} \mathrm{O}$ é facilmente correlacionado com fracionamento de plagioclásio. Fracionamento parece não ter ocorrido no estágio inicial de cristalização, sendo significativo a partir de concentrações de sílica em torno de $51 \%$. A cristalização de piroxênio é retratada pela progressiva correlação negativa de $\mathrm{MgO}$ e $\mathrm{Fe}_{2} \mathrm{O}_{3}$ (também $\mathrm{CaO}$ ) com relação à sílica. A 
Tabela 4 - Composições químicas de elementos maiores e traços em amostras de diques das fazendas Cajazeiras e Maravilha.

\begin{tabular}{|c|c|c|c|c|c|c|c|c|c|c|}
\hline & CAJ-01 & CAJ-03 & CAJ-05 & CAJ-19 & CAJ-20 & CAJ-10 & CAJ-12 & CAJ-15 & MR-04 & MR-08 \\
\hline \multicolumn{11}{|c|}{ Total de óxidos (em \% peso) } \\
\hline $\mathrm{SiO} 2$ & 48,21 & 48,46 & 48,38 & 44,76 & 48,5 & 52,29 & 52,69 & 52,72 & 51,58 & 53,59 \\
\hline $\mathrm{Al} 2 \mathrm{O} 3$ & 14,51 & 14,64 & 14,58 & 12,96 & 14,59 & 14,92 & 14,48 & 14,41 & 14,86 & 13,89 \\
\hline $\mathrm{MnO}$ & 0,144 & 0,139 & 0,15 & 0,167 & 0,135 & 0,139 & 0,137 & 0,138 & 0,138 & 0,108 \\
\hline $\mathrm{MgO}$ & 6,62 & 6,48 & 6,7 & 8,75 & 6,54 & 5,41 & 6,31 & 6,41 & 6,04 & 4,23 \\
\hline $\mathrm{CaO}$ & 8,39 & 8,53 & 8,53 & 8,13 & 8,2 & 8,15 & 7,64 & 7,71 & 7,14 & 6,23 \\
\hline $\mathrm{Na} 2 \mathrm{O}$ & 3,16 & 3,33 & 3,18 & 3,1 & 3,2 & 3,29 & 3,36 & 3,29 & 3,7 & 3,41 \\
\hline $\mathrm{K} 2 \mathrm{O}$ & 1,02 & 0,97 & 0,78 & 1,08 & 0,97 & 0,7 & 0,64 & 0,61 & 0,3 & 1,45 \\
\hline $\mathrm{TiO} 2$ & 2,082 & 2,091 & 1,917 & 1,996 & 2,089 & 1,768 & 1,593 & 1,588 & 1,38 & 2,093 \\
\hline $\mathrm{P} 2 \mathrm{O} 5$ & 0,29 & 0,308 & 0,259 & 0,498 & 0,278 & 0,219 & 0,184 & 0,208 & 0,115 & 0,317 \\
\hline $\mathrm{Fe} 2 \mathrm{O} 3$ & 10,86 & 10,82 & 11,8 & 13,07 & 10,77 & 10,81 & 10,54 & 10,62 & 11,32 & 10,56 \\
\hline LOI & 4,22 & 3,23 & 3,3 & 5 & 3,81 & 1,64 & 1,67 & 1,5 & 2,8 & 3,54 \\
\hline Total & 99,51 & 99 & 99,58 & 99,51 & 99,08 & 99,34 & 99,24 & 99,2 & 99,37 & 99,42 \\
\hline \multicolumn{11}{|c|}{ Total de óxidos recalculados em base anidra (em \% peso) } \\
\hline $\mathrm{SiO} 2$ & 50,6 & 50,6 & 50,25 & 47,36 & 50,91 & 53,52 & 54 & 53,96 & 53,41 & 55,89 \\
\hline $\mathrm{A} 12 \mathrm{O} 3$ & 15,23 & 15,29 & 15,14 & 13,71 & 15,31 & 15,27 & 14,84 & 14,75 & 15,39 & 14,49 \\
\hline $\mathrm{MnO}$ & 0,15 & 0,15 & 0,16 & 0,18 & 0,14 & 0,14 & 0,14 & 0,14 & 0,14 & 0,11 \\
\hline $\mathrm{MgO}$ & 6,95 & 6,77 & 6,96 & 9,26 & 6,86 & 5,54 & 6,47 & 6,56 & 6,25 & 4,41 \\
\hline $\mathrm{CaO}$ & 8,81 & 8,91 & 8,86 & 8,6 & 8,61 & 8,34 & 7,83 & 7,89 & 7,39 & 6,5 \\
\hline $\mathrm{Na} 2 \mathrm{O}$ & 3,32 & 3,48 & 3,3 & 3,28 & 3,36 & 3,37 & 3,44 & 3,37 & 3,83 & 3,56 \\
\hline $\mathrm{K} 2 \mathrm{O}$ & 1,07 & 1,01 & 0,81 & 1,14 & 1,02 & 0,72 & 0,66 & 0,62 & 0,31 & 1,51 \\
\hline $\mathrm{TiO} 2$ & 2,19 & 2,18 & 1,99 & 2,11 & 2,19 & 1,81 & 1,63 & 1,63 & 1,43 & 2,18 \\
\hline $\mathrm{P} 2 \mathrm{O} 5$ & 0,3 & 0,32 & 0,27 & 0,53 & 0,29 & 0,22 & 0,19 & 0,21 & 0,12 & 0,33 \\
\hline $\mathrm{Fe} 2 \mathrm{O} 3$ & 11,4 & 11,3 & 12,26 & 13,83 & 11,3 & 11,06 & 10,8 & 10,87 & 11,72 & 11,01 \\
\hline Total & 100,00 & 100,00 & 100,00 & 100,00 & 100,00 & 100,00 & 100,00 & 100,00 & 100,00 & 100,00 \\
\hline \multicolumn{11}{|c|}{ Norma CIPW } \\
\hline$Q$ & - & - & - & - & - & 4,2 & 3,86 & 4,13 & 2,12 & 7,81 \\
\hline $\mathrm{Or}$ & 6,39 & 6,04 & 4,84 & 6,83 & 6,07 & 4,27 & 3,91 & 3,72 & 1,85 & 9,02 \\
\hline$A b$ & 28,32 & 29,7 & 28,23 & 17,4 & 28,69 & 28,76 & 29,4 & 28,75 & 32,74 & 30,37 \\
\hline$A n$ & 23,71 & 23,31 & 24,33 & 19,53 & 23,91 & 24,65 & 23,29 & 23,48 & 24,09 & 19,26 \\
\hline $\mathrm{Ne}$ & - & - & - & 5,78 & - & - & - & - & - & - \\
\hline$D i(W o)$ & 7,66 & 7,99 & 7,63 & 8,41 & 7,2 & 6,52 & 6,11 & 6,1 & 5,07 & 4,63 \\
\hline$D i(E n)$ & 4,53 & 4,71 & 4,32 & 4,99 & 4,26 & 3,53 & 3,5 & 3,49 & 2,73 & 2,37 \\
\hline$D i(F s)$ & 2,74 & 2,88 & 2,98 & 2,98 & 2,57 & 2,76 & 2,34 & 2,33 & 2,17 & 2,13 \\
\hline$H y(E n)$ & 8,34 & 6,87 & 8,33 & - & 9,81 & 10,33 & 12,69 & 12,93 & 12,94 & 8,67 \\
\hline$H y(F s)$ & 5,03 & 4,2 & 5,74 & - & 5,9 & 8,06 & 8,49 & 8,61 & 10,28 & 7,81 \\
\hline$O l(F o)$ & 3,16 & 3,76 & 3,35 & 12,76 & 2,18 & - & - & - & - & - \\
\hline $\mathrm{Ol}(\mathrm{Fa})$ & 2,1 & 2,53 & 2,55 & 8,4 & 1,45 & - & - & - & - & - \\
\hline$M t$ & 3,02 & 2,99 & 3,17 & 3,55 & 3 & 2,86 & 2,76 & 2,78 & 2,92 & 2,92 \\
\hline $\mathrm{Ilm}$ & 4,19 & 4,19 & 3,82 & 4,06 & 4,2 & 3,47 & 3,13 & 3,11 & 2,74 & 4,18 \\
\hline$A p$ & 0,67 & 0,71 & 0,59 & 1,16 & 0,64 & 0,49 & 0,42 & 0,47 & 0,26 & 0,73 \\
\hline Total & 99,86 & 99,88 & 99,88 & 95,85 & 99,88 & 99,9 & 99,9 & 99,9 & 99,91 & 99,9 \\
\hline \multicolumn{11}{|c|}{ Elementos traços/terras-raras (em ppm) } \\
\hline $\mathrm{Ba}$ & 138,1 & 147,3 & 98,2 & 161,6 & 134,8 & 108,2 & 115,1 & 129,8 & 91,2 & 192,1 \\
\hline $\mathrm{Ga}$ & 19,1 & 19,7 & 16,6 & 19,3 & 18,9 & 19,9 & 20,2 & 19,8 & 18,9 & 22,6 \\
\hline $\mathrm{Hf}$ & 3,5 & 3,8 & 2,6 & 3,7 & 3,7 & 3 & 2,8 & 2,8 & 2 & 3,7 \\
\hline $\mathrm{Nb}$ & 25,6 & 26,9 & 16,1 & 25,1 & 20 & 15,7 & 15,2 & 16,8 & 8 & 28 \\
\hline $\mathrm{Rb}$ & 8,8 & 9,4 & 5,8 & 13,7 & 8,2 & 11,8 & 6,9 & 7,9 & 6,4 & 15,1 \\
\hline $\mathrm{Sr}$ & 544,8 & 573,5 & 462,6 & 709,2 & 557,9 & 412,4 & 423 & 417,8 & 274,4 & 564,1 \\
\hline $\mathrm{Ta}$ & 9,9 & 8,3 & 5,4 & 2,1 & 4,2 & 6,6 & 7 & 8,9 & 5 & 5,9 \\
\hline Th & 1 & 1,3 & 0,7 & 1,9 & 1,2 & 0,7 & 0,7 & 0,8 & 0,9 & 1,2 \\
\hline U & 0,6 & 0,6 & 0,4 & 0,7 & 0,5 & 0,4 & 0,3 & 0,3 & 0,2 & 0,6 \\
\hline V & 199 & 204 & 157 & 186 & 200 & 162 & 166 & 163 & 143 & 112 \\
\hline $\mathrm{Zr}$ & 131,8 & 144,8 & 90,8 & 145,9 & 135,8 & 97,4 & 96,4 & 90,9 & 59 & 126,2 \\
\hline $\mathrm{Y}$ & 17,4 & 18,8 & 13,6 & 18 & 17,4 & 17,9 & 18 & 18,3 & 14,9 & 15,1 \\
\hline $\mathrm{La}$ & 13,4 & 14,8 & 9,3 & 24 & 12,8 & 8,6 & 8,2 & 8,6 & 4,1 & 12,7 \\
\hline $\mathrm{Ce}$ & 30,3 & 33,7 & 21,3 & 51,6 & 29,7 & 19,4 & 18,6 & 19,8 & 10,1 & 28 \\
\hline $\operatorname{Pr}$ & 3,69 & 3,93 & 2,67 & 5,97 & 3,6 & 2,56 & 2,41 & 2,57 & 1,45 & 3,56 \\
\hline $\mathrm{Nd}$ & 17,4 & 17,9 & 12,3 & 25,9 & 16,9 & 12,8 & 12 & 12,8 & 8,3 & 16,9 \\
\hline $\mathrm{Sm}$ & 4,1 & 4,7 & 3,4 & 5,6 & 4,1 & 3,7 & 3,8 & 3,7 & 3,1 & 4,7 \\
\hline $\mathrm{Eu}$ & 1,5 & 1,68 & 1,27 & 1,88 & 1,5 & 1,46 & 1,5 & 1,37 & 1,19 & 1,81 \\
\hline $\mathrm{Gd}$ & 4,49 & 4,89 & 3,11 & 5,37 & 4,29 & 4,18 & 4,21 & 4,18 & 3,3 & 4,7 \\
\hline $\mathrm{Tb}$ & 0,68 & 0,79 & 0,5 & 0,78 & 0,65 & 0,69 & 0,66 & 0,67 & 0,56 & 0,68 \\
\hline Dy & 3,34 & 3,71 & 2,55 & 3,76 & 3,53 & 3,5 & 3,52 & 3,42 & 3,01 & 3,39 \\
\hline Ho & 0,67 & 0,66 & 0,47 & 0,66 & 0,6 & 0,64 & 0,66 & 0,64 & 0,52 & 0,53 \\
\hline $\mathrm{Er}$ & 1,7 & 1,78 & 1,35 & 1,7 & 1,7 & 1,66 & 1,77 & 1,85 & 1,51 & 1,2 \\
\hline $\mathrm{Tm}$ & 0,24 & 0,26 & 0,19 & 0,23 & 0,2 & 0,23 & 0,23 & 0,23 & 0,19 & 0,15 \\
\hline $\mathrm{Yb}$ & 1,32 & 1,43 & 0,99 & 1,26 & 1,35 & 1,37 & 1,41 & 1,47 & 1,28 & 0,93 \\
\hline $\mathrm{Lu}$ & 0,2 & 0,22 & 0,17 & 0,2 & 0,22 & 0,21 & 0,19 & 0,21 & 0,18 & 0,12 \\
\hline $\mathrm{Pb}$ & 0,5 & 0,6 & 0,3 & 0,7 & 0,5 & 0,8 & 0,3 & 0,4 & 0,6 & 0,3 \\
\hline $\mathrm{Zn}$ & 58 & 78 & 66 & 74 & 51 & 79 & 66 & 72 & 71 & 97 \\
\hline $\mathrm{Ni}$ & 72 & 57,3 & 334.8 & 139.4 & 66,3 & 41,6 & 45,6 & 49,9 & 83,9 & 38,3 \\
\hline
\end{tabular}




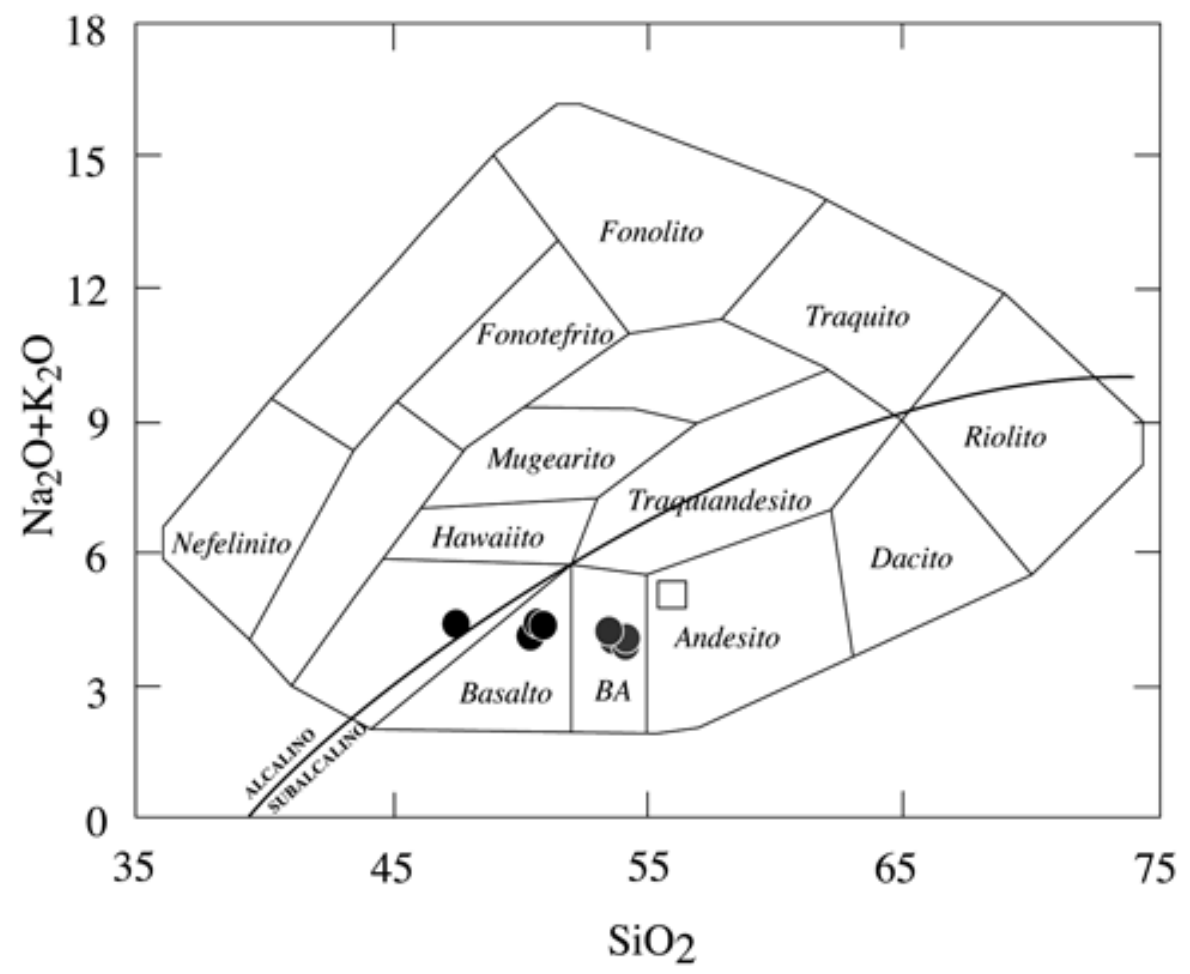

Figura 6 - Diagrama de classificação geoquímica para rochas vulcânicas, com campos definidos por Cox et al. (1979). Os dados plotados referem-se àqueles calculados em base anidra. Legenda: círculo preto: amostras CAJ-19 (olivina basalto), CAJ-01, -03, -05 e -20 (basaltos); círculo cinza: CAJ-10, -12 e -15 e MAR-04 (basaltos andesíticos); quadrado: MAR-08 (andesito).

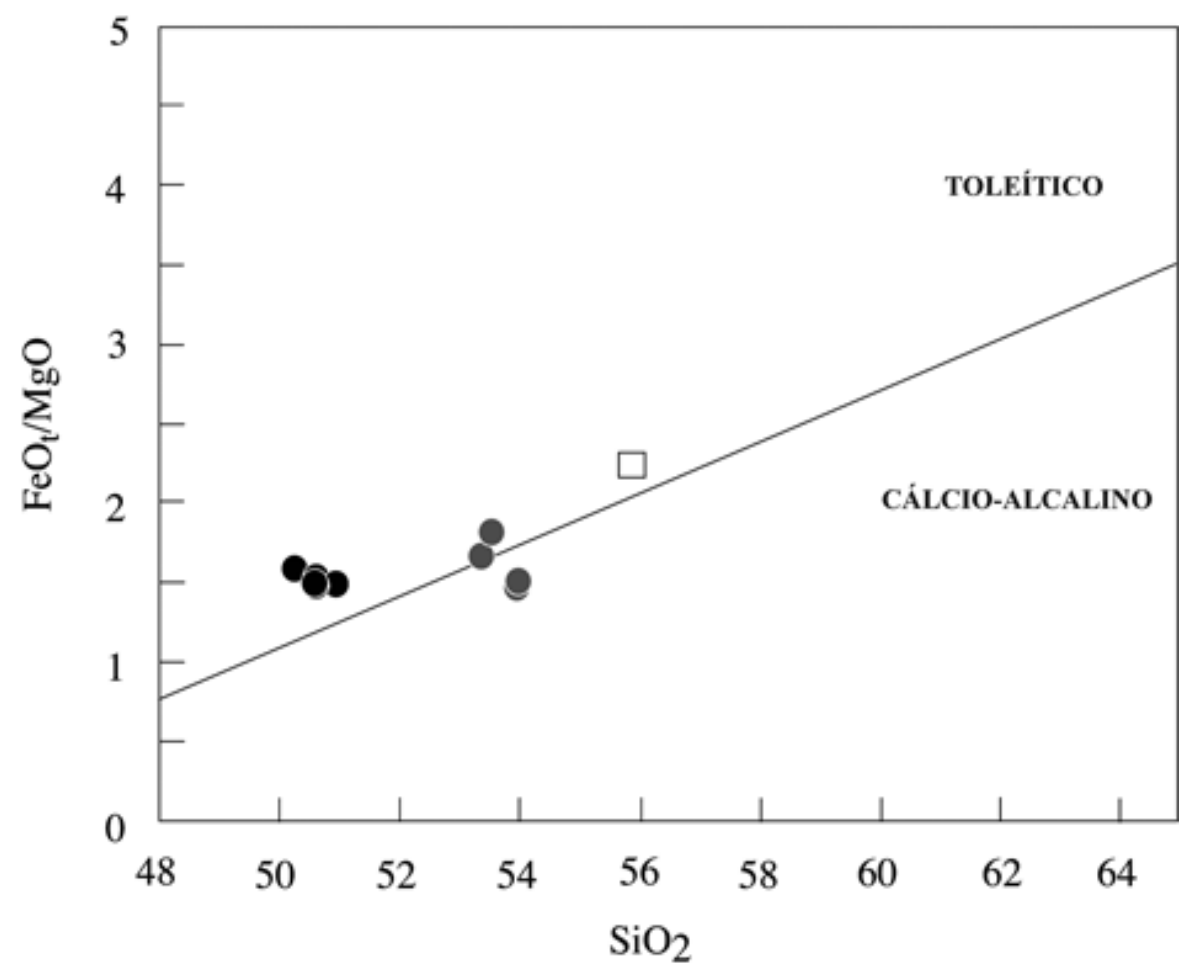

Figura 7 - Diagrama FeOt/MgO versus sílica com divisão entre as séries toleitica e cálcio-alcalina segundo Irvine e Baragar (1971). Legenda: círculo preto: amostras CAJ-19 (olivina basalto), CAJ-01, -03, -05 e -20 (basaltos); circulo cinza: CAJ-10, -12 e -15 e MAR-04 (basaltos andesíticos); quadrado: MAR-08 (andesito). 

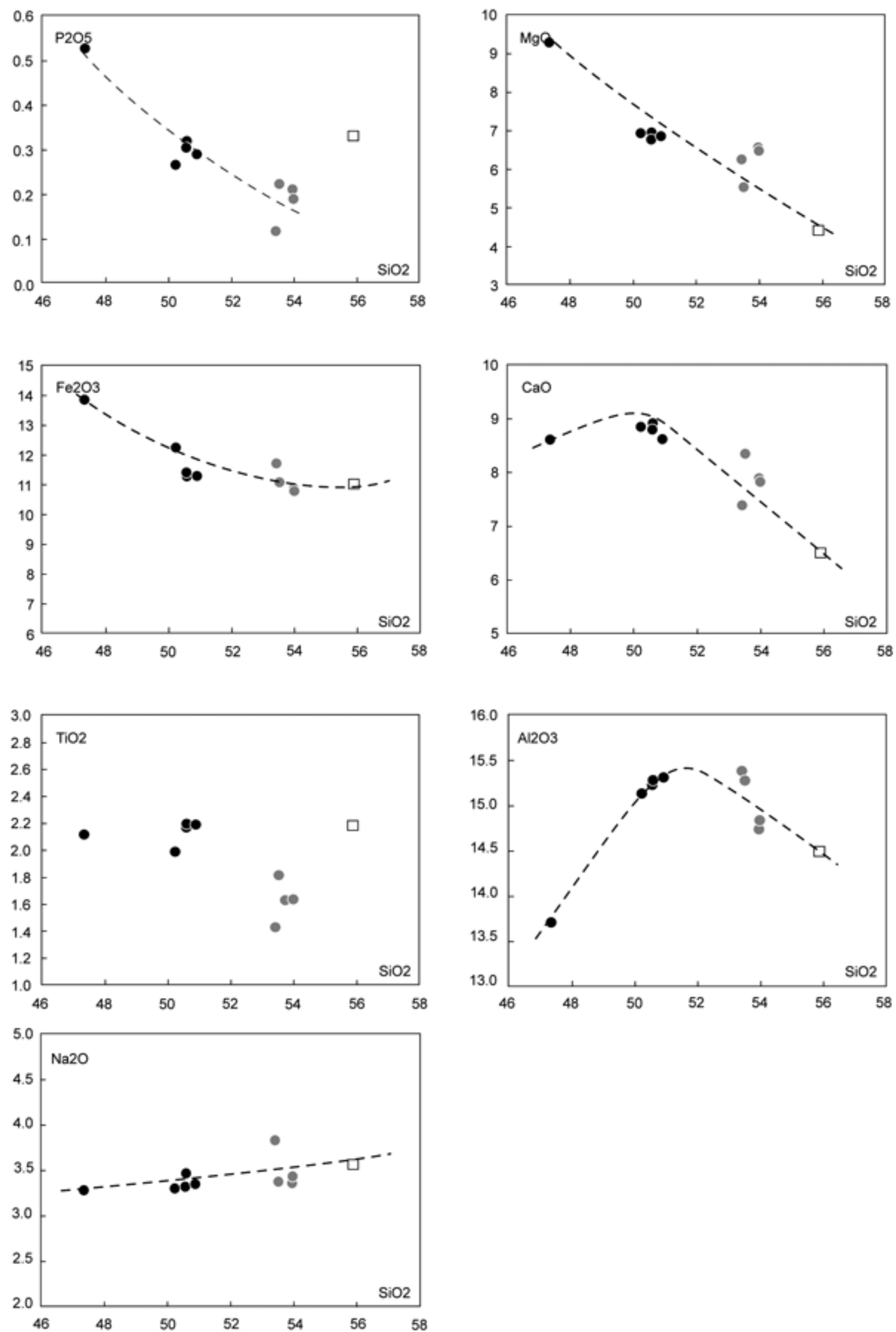

Figura 8 - Diagramas de variação entre óxidos (tipo Harker). Os dados plotados são aqueles calculados em base anidra, conforme a tabela 4. Legenda: círculo preto: amostras CAJ-19 (olivina basalto), CAJ-01, -03, -05 e-20 (basaltos); círculo cinza: CAJ-10, - 12 e -15 e MAR-04 (basaltos andesiticos); quadrado: MAR-08 (andesito). 
correlação positiva entre $\mathrm{CaO}$ e $\mathrm{MgO}$ indica que piroxênio e plagioclásio foram fases co-precipitadas a partir de níveis de sílica em torno de $50 \%$. Decréscimo de Ti pode ter sido induzido pelo fracionamento de ilmenita e piroxênio (titanoaugita), especialmente evidente nos estágios mais precoces da evolução do magma. O discreto aumento em Al no início da cristalização pode ser também explicado pelo fracionamento mais significativo de (clino)piroxênio neste estágio, o qual é uma fase pobre neste elemento.

Os diagramas de variação entre óxidos sugerem que cristalização fracionada pode ter sido o processo petrogenético dominante, com retirada progressiva de $\mathrm{Ca}, \mathrm{Fe}, \mathrm{Mg}$ e Ti como função da cristalização de plagioclásio, piroxênio, olivina e ilmenita. Um exercício adicional para testar a hipótese de cristalização fracionada pode ser obtido a partir de diagramas de correlação entre elementos compatíveis e incompatíveis. Todavia, o teste dessa hipótese para os diques da região de Itabaiana é limitado devido: (i) à forte mobilidade dos elementos $\mathrm{Rb}, \mathrm{Ba}$ e $\mathrm{K}$ como resultado da alteração microscópica observada, e (ii) a ausência de um elemento com comportamento fortemente compatível. Como conseqüência, não foram observadas tendências que pudessem confirmar (ou não) esse processo.
Geoquímica de elementos traços Quando analisados os gráficos de comportamento geoquímico para elementos traços (multielementos; Fig. 9) e terras-raras (ETR; Fig. 10), observa-se que os diques basálticos CAJ-19 e CAJ-20 apresentam espectros um pouco distinto dos demais. Em conjunto, os espectros multielementos mostram: (i) enriquecimento moderado (c. 1080 vezes o condrito) em elementos incompatíveis ( $\mathrm{Ba}$, $\mathrm{Rb}, \mathrm{Th}, \mathrm{K}, \mathrm{La}, \mathrm{Ce}$ ), (ii) forte anomalia negativa em $\mathrm{P}$, provavelmente resultante do fracionamento de apatita, e (iii) significativa anomalia positiva em $\mathrm{Sr}$ que, combinada à ausência de anomalias em Eu, sugere que plagioclásio não foi uma fase importante no processo de fracionamento magmático. O olivina-basalto alcalino (CAJ-19) mostra enriquecimento discretamente maior em $\mathrm{Th}, \mathrm{Sr}$ e terras-raras leves, este último refletido no padrão mais fracionado $\left((\mathrm{La} / \mathrm{Yb})_{\mathrm{N}} 12,8\right)$ observado na figura 10. Os olivina-basaltos toleíticos mostram padrões ETR homogêneos $\left[(\mathrm{La} / \mathrm{Yb})_{\mathrm{N}} 6,33-6,98\right]$, à exceção do dique CAJ-20 que mostra menor fracionamento dos terras-raras, com $(\mathrm{La} / \mathrm{Yb})$ de 2,16. Já os espectros obtidos para os quartzo-basalto toleíticos são relativamente menos fracionados que a média dos olivina-basaltos, com $\left[(\mathrm{La} / \mathrm{Yb})_{\mathrm{N}}\right.$ entre 3,92-4,23)], muito embora dois dos diques deste conjunto definam espectros mais

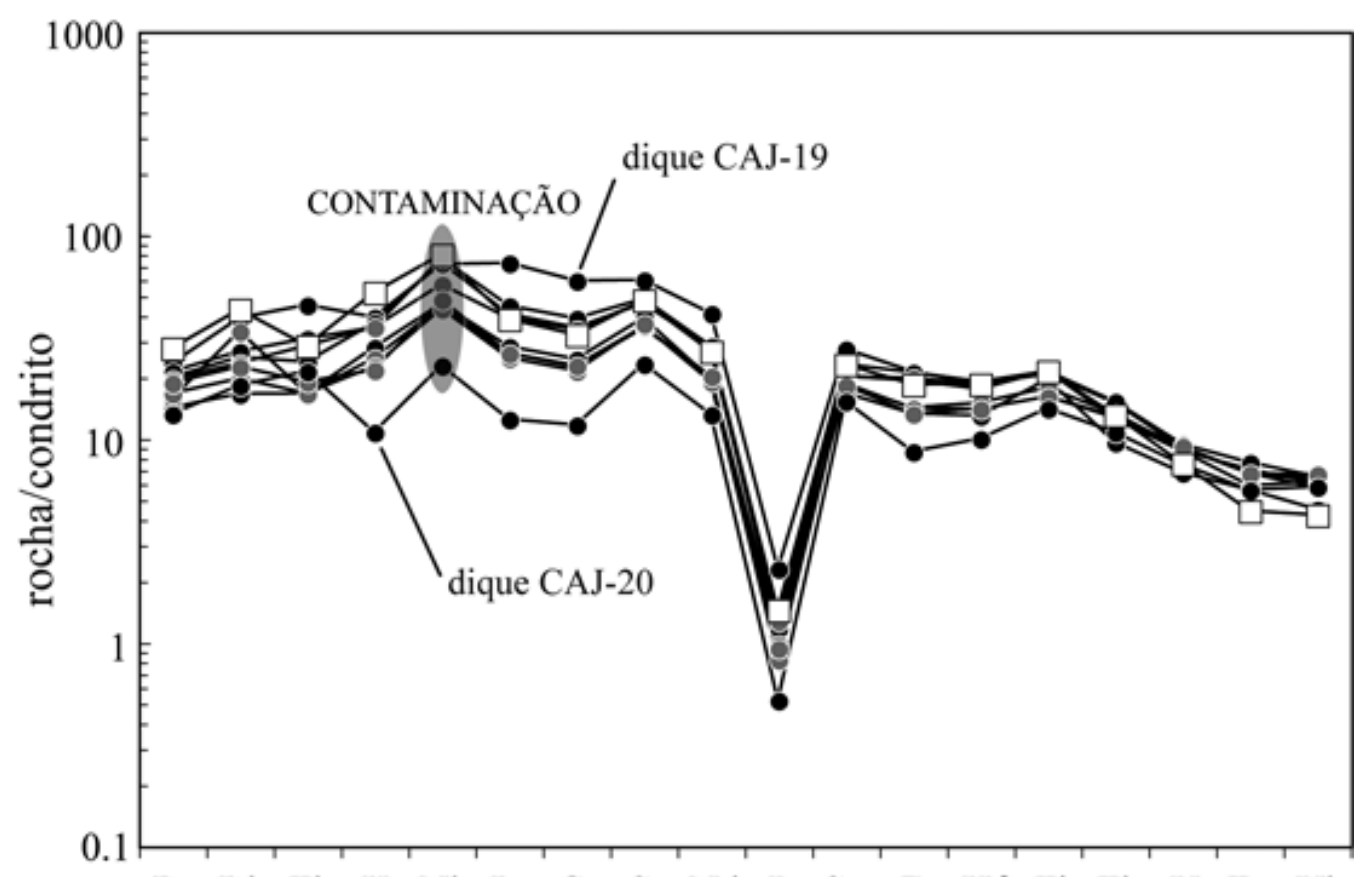

$\mathrm{Ba} \mathrm{Rb}$ Th $\mathrm{K}$ Nb La Ce Sr Nd P Sm Zr Hf Ti Tb Y Tm Yb

Figura 9 - Diagrama multielementos normalizado ao condrito de Thompson (1982). As amostras foram plotadas individualmente. Os teores obtidos para $\mathrm{Nb}$ mostram discreto enriquecimento em relação aos elementos vizinhos; esta feição está relacionada à pulverização das amostras em moinho de carbeto de tungstênio, o qual promove algum grau de contaminação neste elemento. Legenda: circulo preto: amostras CAJ-19 (olivina basalto), CAJ-01, -03, -05 e -20 (basaltos); círculo cinza: CAJ-10, -12 e -15 e MAR-04 (basaltos andesiticos); quadrado: MAR-08 (andesito). 


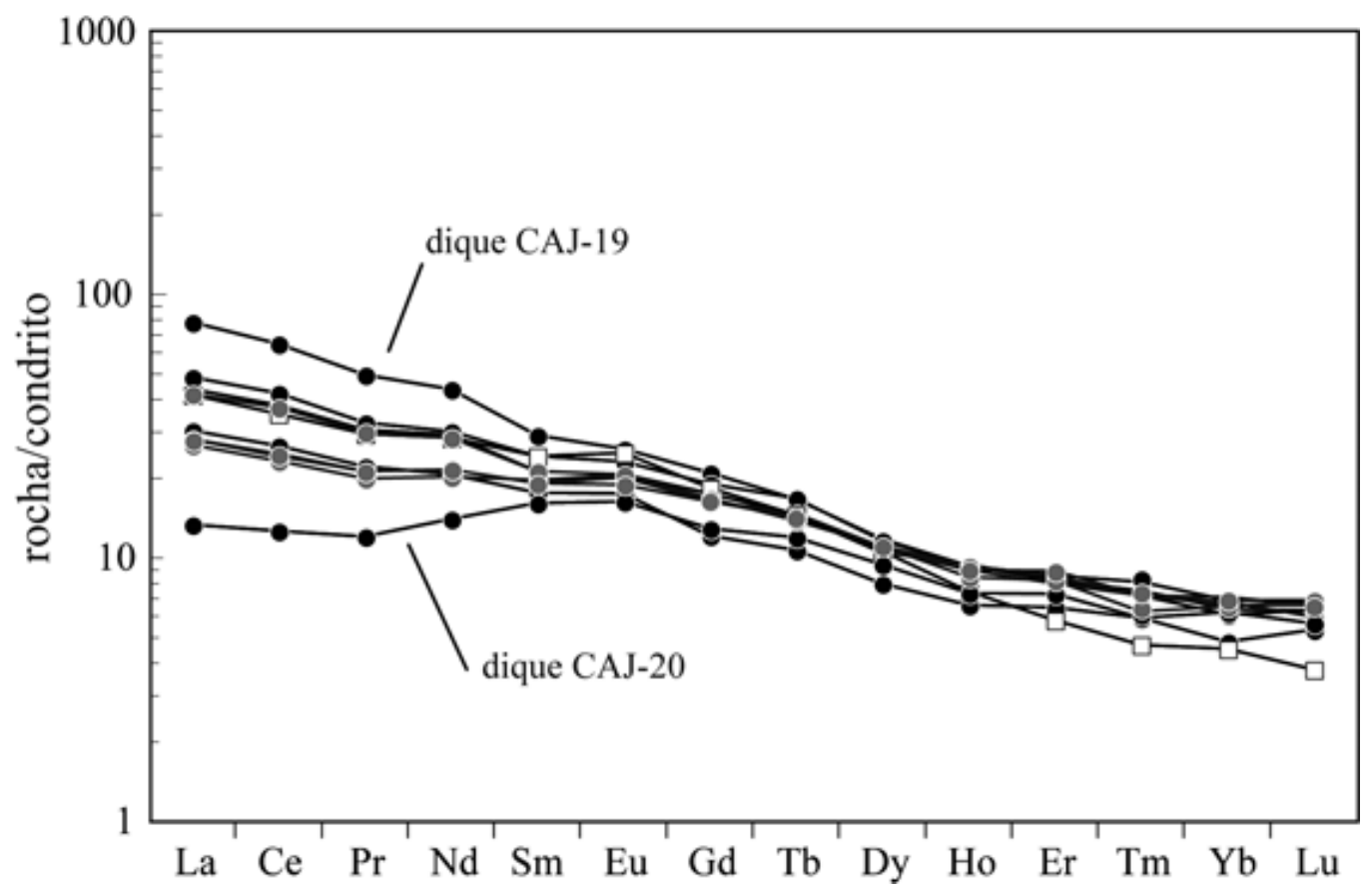

Figura 10 - Diagrama ilustrando o comportamento geoquímico dos elementos terras-raras nas amostras estudadas. A normalização refere-se ao condrito de Boynton (1984). Legenda: circulo preto: amostras CAJ-19 (olivina basalto), CAJ-01, -03, -05 e -20 (basaltos); circulo cinza: CAJ-10, -12 e -15 e MAR-04 (basaltos andesíticos); quadrado: MAR-08 (andesito).

fracionados, com $(\mathrm{La} / \mathrm{Yb})_{\mathrm{N}}$ de 6,39 (MR-04) e 9,31 (MR-08).

CONCLUSÕES O conjunto de diques estudado representa um episódio magmático fissural, de natureza máfica e de idade cambriana (c. $525 \mathrm{Ma})$. Sua importância diz respeito à correlação com um período de transição entre intensa atividade tectono-magmática (Neoproterozóico/Ciclo Brasiliano) e outro de aparente quiescência (Paleozóico) na Província Borborema. Todavia, tendo em vista sua ocorrência espacial e volumétrica restrita, qualquer interpretação do ponto de vista geodinâmico deve ser conduzida com cautela podendo ser, a priori, tentativamente correlacionada com a formação de bacias intracratônicas paleozóicas.

Do ponto de vista petrográfico os diques diferenciam-se por aspectos microtexturais, natureza dos microfenocristais, e pela composição dos (clino)piroxênios na matriz. Nesse último caso, uma tendência a composições variáveis é observada em piroxênios da matriz dos diques com microfenocristais de olivina e nos diques faneríticos, as quais podem refletir a presença de lamelas de exsolução de pigeonita em augita, em uma escala não facilmente visível em seção delgada. Olivina $\left(\mathrm{Fo}_{76-84}\right)$ e plagioclásio (dominantemente labradorita) são fases relativamente homogêneas entre os diques estudados. Substituição total ou parcial de olivina e, em menor proporção, (clino) piroxênio por iddingsita/bowlingita indicam a presença de fluidos interagin- do, provavelmente, em condições tardi-magmáticas; a ausência de feições texturais/mineralógicas sugestivas de alteração na encaixante, ao longo do contato com os diques, enfraquece a hipótese de alteração supergênica, pós-cristalização.

A análise litoquímica dos diques permitiu caracterizá-los como uma série subalcalina constituída por basaltos, basaltos andesíticos e andesito com afinidade toleítica; somente um dos diques mostra clara filiação alcalina. A similaridade entre os espectros multielementos de todo o conjunto de diques estudado sugere origem a partir de uma fonte comum, moderadamente (em relação ao condrito) enriquecida em elementos incompatíveis tais como $\mathrm{Rb}, \mathrm{Ba}, \mathrm{Th}, \mathrm{K}$ e terras-raras leves, e em menor proporção em elementos imóveis ( $\mathrm{Zr}$, Hf, Ti). As discretas diferenças em termos de fracionamento nos espectros ETR sugerem que pequenas variações em percentagens de fusão parcial possam estar associadas à evolução destes magmas, visto que fases minerais ricas em ETR parecem não estar envolvidas na história de fracionamento magmático.

Agradecimentos Este artigo reúne os resultados apresentados na monografia de conclusão do curso de graduação em Geologia de V.V. Almeida. As autoras agradecem à Fundação de Amparo à Pesquisa do Estado de São Paulo - FAPESP, pelo apoio financeiro ao projeto 04/08614-9 "O Cambro-Ordoviciano na Província Borborema", coordenado por M.H.B.M. Hollanda, cujos recursos financiaram esta pesquisa. 


\section{Referências}

Archanjo C.J., Trindade R.I.F., Bouchez J.L., Ernesto M. 2002. Granite fabrics and regional-scale strain partitioning in the Seridó belt (Borborema Province, NE Brazil). Tectonics, 21(1):1-13.

Almeida F.F.M., Hasui Y., Brito Neves B.B., Fuck R.A. 1977. Províncias Estruturais Brasileiras. In: SBG, Simp. Geol. Nordeste, 8, Anais, p. 363-391.

Bellieni G., Macedo M.H.F., Petrini R., Piccirillo E.M., Cavazzini G., Comim-Chiaramonti P., Ernesto M., Macedo J.W.P., Martins G., Melfi A.J., Pacca I.G., de Min A., 1992. Evidence of magmatic activity related to Middle Jurassic and lower Cretaceous rifting from northeastern Brazil (Ceará-Mirim): K/Ar age, paleomagnetism, petrology and $\mathrm{Sr}-\mathrm{Nd}$ isotope characteristics. Chemical Geology, 97:9-32.

Boynton W.V. 1984. Geochemistry of the rare earth elements: meteorite studies. In: Henderson P. (ed.) Rare earth element geochemistry. Elsevier, p. 63-114.

Brito Neves B.B. 1988. The Cambro-Ordovician of the Borborema Province. Boletim IG-USP, Série Científica 29:175-193.

Brito Neves B.B., Van Schmus W.R., Santos E.J., Campos Neto M.C., Kozuch M. 1995. O evento Cariris Velhos na Província Borborema. Revista Brasileira de Geociências, 25:279-296.

Brito Neves B.B., Santos E.J., Van Schmus W.R. 2000. Tectonic History of the Borborema Province, Northeastern Brazil. In: Cordani U.G., Milani E.J., Thomaz Filho A., Campos D.A (ed.) Tectonic Evolution of South American. Rio de Janeiro, p. 151-182.

Brito Neves B.B., Campos Neto M.C., Van Schmus W., Santos E.J. 2001a. O "Sistema Pajeú-Paraíba" e o Maciço São José do Campestre no leste da Borborema. Revista Brasileira de Geociências, 31(2):173-184.

Brito Neves B.B., Campos Neto M.C., Van Schmus W., Fernandes T.M.G., Souza S.L. 2001b. O Terreno Alto Moxotó no leste da Paraíba ("Maciço Caldas Brandão"). Revista Brasileira de Geociências, 31(2):185-194.

Fernandes T.M.G. 1997. Estudos geológicos e geocronológicos complementares na parte sul do Maciço Caldas Brandão-PB. Rio Claro, Dissertação de Mestrado, Instituto de Geociências, Universidade
Estadual de São Paulo, 106 p.

Hollanda M.H.B.M., Pimentel M.M., Oliveira D.C., Jardim de Sá E.F. 2006. Lithosphere-asthenosphere interaction and the origin of Cretaceous tholeiitic magmatism in northeastern Brazil: Sr-Nd-Pb isotopic evidence. Lithos, 86:34-49.

Irvine T.N. \& Baragar W.R.A. 1971. A guide to the chemical classification of the common volcanic rocks. Canadian Journal of Earth Sciences, 8:523-548.

Mori P.E., Reeves S., Correia C.T., Haukka M. 1999. Development of a fused glass disc xrf facility and comparison with the pressed powder pellet technique at Instituto de Geociências, São Paulo University. Revista Brasileira de Geociências, 29(3):441-446.

Santos E.J. 1995. O Complexo Granítico Lagoa das Pedras: Acresção e Colisão na Região de Floresta (Pernambuco), Província Borborema. Tese de Doutoramento, Instituto de Geociências, Universidade de São Paulo, São Paulo, 219 p.

Santos E.J. 1996. Ensaio preliminar sobre terrenos e tectônica acrescionária na Província Borborema. In: SBG, Cong. Bras. Geologia, 39, Anais, p. 47-50.

Santos E.J. 1999. Belém do São Francisco, Folha SC.24X-A: estados de Pernambuco, Alagoas e Bahia. Brasília, Programa de Levantamentos Geológicos Básicos do Brasil - CPRM, 84 p.

Santos E.J., Nutman A.P., Brito Neves B.B. 2004. Idades SHRIMP U-Pb do Complexo Sertânia: implicações sobre a evolução tectônica da Zona Transversal, Província Borborema. Geologia USP, Série Científica, 4:1-12.

Thompson R.N. 1982. British Tertiary volcanic province. Scott. Journal of Geology, 18:49-107.

Trindade R.I.F., D’Agrella-Filho M.S., Epof I., Brito Neves B.B. 2006. Paleomagnetism of Early Cambrian Itabaiana mafic dikes (NE Brazil) and the final assembly of Gondwana. Earth Planetary Science Letters, 244:361377.

ID 12923

Submetido em 01/12/2008 Aceito em 16/10/2009 